\title{
Exploring Functional Differences between the Right and Left Ventricles to Better Understand Right Ventricular Dysfunction
}

\author{
Judith Bernal-Ramirez ${ }^{(D)}{ }^{1}$ Magda C. Díaz-Vesga $\left(\mathbb{D},{ }^{2,3,4,5,6}\right.$ Matias Talamilla, ${ }^{2}$ \\ Andrea Méndez, ${ }^{2,5,7,8}$ Clara Quiroga $\mathbb{D}^{1}{ }^{3,9}$ Javier A. Garza-Cervantes $\left.{ }^{(D)}\right)^{1}$ \\ Anay Lázaro-Alfaro $\mathbb{D}$, ${ }^{1}$ Carlos Jerjes-Sanchez $\mathbb{D}$, ${ }^{1,10}$ Mauricio Henríquez $\mathbb{D},{ }^{2,5}$ \\ Gerardo García-Rivas $\mathbb{D}^{1,10}$ and Zully Pedrozo ${ }^{10,3,4,5}$
}

${ }^{1}$ Tecnológico de Monterrey, Escuela de Medicina y Ciencias de la Salud, Ave. Morones Prieto 3000, Monterrey, NL 64710, Mexico

${ }^{2}$ Programa de Fisiología y Biofísica, Instituto de Ciencias Biomédicas, Facultad de Medicina, Universidad de Chile, Santiago de Chile, Chile

${ }^{3}$ Advanced Center for Chronic Diseases, Facultad de Ciencias Químicas y Farmacéuticas \& Facultad Medicina, Universidad de Chile, Santiago de Chile, Chile

${ }^{4}$ Centro de Estudios en Ejercicio, Metabolismo y Cáncer (CEMC), Facultad de Medicina, Universidad de Chile, Santiago de Chile, Chile

${ }^{5}$ Red para el Estudio de Enfermedades Cardiopulmonares de Alta Letalidad (REECPAL), Universidad de Chile, Santiago de Chile, Chile

${ }^{6}$ Grupo de Investigación en Ciencias Básicas y Clínicas de la Salud, Pontificia Universidad Javeriana de Cali, Colombia

${ }^{7}$ Escuela de Kinesiología, Facultad de Salud y Ciencias Sociales, Campus Providencia, Sede Santiago,

Universidad de las Américas, Chile

${ }^{8}$ Centro de Investigación e Innovación Biopsicosocial en Enfermedades Crónicas, Facultad de Salud y Ciencias Sociales, Universidad de las Américas, Chile

${ }^{9}$ División de Enfermedades Cardiovasculares, Facultad de Medicina, Pontificia Universidad Católica de Chile, Santiago, Chile

${ }^{10}$ Tecnológico de Monterrey, Centro de Investigación Biomédica, Hospital Zambrano Hellion, TecSalud, San Pedro Garza Garcia, NL 66278, Mexico

Correspondence should be addressed to Gerardo García-Rivas; gdejesus@itesm.mx and Zully Pedrozo; zpedrozo@uchile.cl

Received 24 March 2021; Accepted 4 August 2021; Published 30 August 2021

Academic Editor: Gaetano Santulli

Copyright $\odot 2021$ Judith Bernal-Ramirez et al. This is an open access article distributed under the Creative Commons Attribution License, which permits unrestricted use, distribution, and reproduction in any medium, provided the original work is properly cited.

The right and left ventricles have traditionally been studied as individual entities. Furthermore, modifications found in diseased left ventricles are assumed to influence on right ventricle alterations, but the connection is poorly understood. In this review, we describe the differences between ventricles under physiological and pathological conditions. Understanding the mechanisms that differentiate both ventricles would facilitate a more effective use of therapeutics and broaden our knowledge of right ventricle (RV) dysfunction. RV failure is the strongest predictor of mortality in pulmonary arterial hypertension, but at present, there are no definitive therapies directly targeting RV failure. We further explore the current state of drugs and molecules that improve RV failure in experimental therapeutics and clinical trials to treat pulmonary arterial hypertension and provide evidence of their potential benefits in heart failure. 


\section{Introduction}

Pulmonary arterial hypertension (PAH) is an incurable lifelimiting disease characterized by increased pulmonary hypertension secondary to pulmonary vasculature remodeling [1]. The increased pressure overloads the right ventricle $(\mathrm{RV})$, inducing adaptative RV remodeling. In the initial stages, RV hypertrophy decreases wall tension, but maladaptive remodeling induces RV dysfunction and right heart failure syndrome in the end stages [2]. Specific treatment includes therapies targeting endothelin, nitric oxide, and prostacyclin pathways in pulmonary arteries to decrease pulmonary pressure and prevent RV stress [3]. The available therapeutic approaches improve quality of life and reduce the incidence of clinical worsening [4]. Although RV dysfunction and the patient's response to $\mathrm{PAH}$-specific treatment determine survival $[5,6]$, there are no therapeutic aims to improve RV dysfunction [7]. Left ventricular (LV) dysfunction mechanisms have been widely studied, and multiple therapies to improve LV failure survival are available [8]; however, treatment for RV dysfunction is less robust [9]. Notably, beta-blockers and drugs that target the renin-angiotensinaldosterone system (RAAS), which are standard therapies for LV failure, are potentially contraindicated in RV dysfunction [8]. Thus, understanding the differences between the RV and LV and describing RV dysfunction's underlying mechanism may be essential to outline an RV-directed therapy and improve PAH patient outcomes. This review focuses on the underlying mechanisms that differentiate left and right ventricles in both physiological conditions and disease development.

\section{Structural and Functional Differences between the Right and Left Ventricles}

The heart is a muscular pump whose primary function is to supply blood to the body, allowing oxygen and nutrients to reach each cell while removing carbon dioxide and metabolic waste. The ventricles propel blood from the heart to either high-pressure systemic circulation by the thick-walled conicshaped LV or pulmonary circulation by the thin-walled, crescent-shaped RV, which is capable of maintaining low pressure levels even under changes in volume $[10,11]$. Both ventricles adapt their mechanisms at the cellular and tissue levels to meet the whole organism's needs and their development into adulthood to accomplish the heart's function. This section summarizes the differences in development and adaptations of each ventricle to maintain its proper function.

2.1. Structural Differences between Ventricles. Embryonic development of the human cardiovascular system occurs between the third and eighth weeks of gestation [12]. Specifically, heart development begins on the 16th day of gestation; however, it is not a uniform process. Ventricles show differences in development, cellular origin, and molecular and genetic markers. These differences begin with the movement of cardiac progenitor cells that originate in gastrulation, from the mesoderm to the anterior of the primitive vein [13], where two structures are differentiated: the first cardiac field (FHF) and the second cardiac field (SHF) [14]. The FHF will give origin to the crescent-shaped cardiac tube and the LV, which begins development before the RV. The SHF will give origin to the outflow tract and the RV. It is essential to note that these processes develop successively and under genetic control, including the Paired-Like Homeodomain 2 (PITX2) gene, which determines left and right asymmetry [13], and the Heart and Neural Crest Derivatives Expressed (HAND1 and HAND2) genes, which influence the development of the left and right ventricles, respectively, [14]. Contrary to what happens in adulthood, where cardiac output is the same for both ventricles, during embryological development, the RV produces $60 \%$ of total cardiac output [11]. Likewise, during embryological development, the thickness and strength generated by the LV and RV are the same [12].

An organ's structure serves its function; thus, differences in the pressure of pulmonary and systemic circuits determine several structural differences between ventricles. Noting the anatomical muscle arrangement in both ventricles helps to understand how blood is pumped through different parts of the circulatory system. Most of the muscle fibers in the RV free wall are transverse fibers with a small portion of subendocardial longitudinal fibers [15]. However, the LV is composed of endocardial and epicardial fibers, which form a helical structure, and circumferential fibers located at the midwall [16]. Therefore, RV needs fewer muscle fibers and is much thinner than the LV, and it has about one-third of LV's thickness [10]. This fiber arrangement contributes differently to ventricle contraction. LV contraction involves the septum, presenting a radial constriction and longitudinal shortening, contributing $67 \%$ and $33 \%$ to the LV ejection fraction (LVEF), respectively [16]. Simultaneously, longitudinal fibers in the RV free wall account for $20-30 \%$ of the $\mathrm{RV}$ ejection fraction (RVEF). In comparison, approximately $80 \%$ of RV systolic function is attributed to the septum's helical fibers, which twist and shorten the longitudinal axis in the RV [15]. Along with differences in fiber arrangement and muscle contraction, the RV has a higher extracellular matrix content than the LV [17].

2.2. Physiological Difference between Ventricles. Anatomical differences between the ventricles are also reflected in their perfusion system. The lower pulmonary arterial pressure and pulmonary vascular resistance are $20 \%$ and $10 \%$ of systemic arterial pressure and systemic vascular resistance, respectively [18], leading to lower oxygen consumption by the RV [19]. While the LV has a higher oxygen demand, its perfusion predominantly occurs during diastole due to the fact that increased intramural pressure during systole impedes the flow supply [19]. The low pressures handled by the RV allow the perfusion of blood flow throughout the entire cardiac cycle, allowing it to maintain an appropriate myocardial oxygen level [19]. Moreover, the collateral vessels of the RV are denser than those of the LV [10]. The lower oxygen consumption and blood flow in the RV result in an oxygen extraction reserve, making the RV less vulnerable to myocardial ischemia [19]. However, the RV is highly susceptible to acute increases in afterload, unlike the $\operatorname{LV}[20,21]$. 
Increases in pulmonary arterial pressure increase intramural pressure, impeding blood supply during systole, which increases blood flow demands during diastole, like LV perfusion [19]. After the blood flow fails to meet an acute or chronic increased oxygen demand caused by an increased afterload, it results in RV ischemia and RV failure [19, 22].

\subsection{Differences in Cell Shortening and Relaxation between} Cardiac Cells. The cardiac muscle's functional unit is the cardiomyocyte, whose primary function is to accomplish the cell contraction-relaxation cycle, leading to synchronized organ contraction and relaxation [23]. This synchronization is made possible by cardiac excitation-contraction coupling (ECC), which is the physiological process of converting an electrical stimulus to a mechanical response [24]. ECC refers to everything from the activation of the calcium ion $\left(\mathrm{Ca}^{2+}\right)$ transient by initial membrane depolarization, through the action potential (AP), to myofilament contraction in response to increased intracellular $\mathrm{Ca}^{2+}$. The initial AP promotes the entry of extracellular $\mathrm{Ca}^{2+}$ through voltage-dependent $\mathrm{Ca}^{2+}$ channels at the plasma membrane or sarcolemma, which promotes the release of $\mathrm{Ca}^{2+}$ from the sarcoplasmic reticulum (SR) in a process known as calcium-induced calcium release (CICR), causing a significant transient increase in intracellular $\mathrm{Ca}^{2+}[24]$, which interacts with the proteins in myofilaments to produce cellular contraction. Cell relaxation occurs by removing cytosolic $\mathrm{Ca}^{2+}$ in a highly energy-dependent process [25]. This section will focus on describing the differences between left and right cardiomyocytes during ECC, especially the differential characteristics of AP, components of $\mathrm{Ca}^{2+}$ handling in myocytes, and energetic and mitochondria-dependent process in excitation energetic coupling.

By definition, AP involves a reversible change in membrane potential due to the sequential activation and inhibition of several ionic channels, which allow ions to flow in favor of their electrochemical gradient through the cell membrane [26]. Sodium ion $\left(\mathrm{Na}^{+}\right)$and $\mathrm{Ca}^{2+}$ inward currents and different potassium ion $\left(\mathrm{K}^{+}\right)$outward currents are described in this section. Differences in AP form and duration (APD) are explained by changes in the expression and function of these ions' channels (Table 1). Figure 1 highlights the main differences between the right and left AP shape and currents. Membrane depolarization by AP starts with a sodium inward current $\left(I_{\mathrm{Na}}\right)$ through voltage-sensitive $\mathrm{Na}^{+}$channels. Higher $I_{\mathrm{Na}}$ densities and larger $\mathrm{Na}^{+}$currents have been found in the $\mathrm{LV}$ than in the RV. In the $\mathrm{LV}, \mathrm{Na}^{+}$channels also have more negative steady-state inactivation, $V_{1 / 2}$, and slower recovery from inactivation than in the RV, without changes in the activation threshold [26]. The lower $I_{\mathrm{Na}}$ density causes a slower conduction time in the $\mathrm{RV}$, resulting in a lower upstroke velocity [26]. Despite the lower density, higher [27] or unchanged [26] $\mathrm{Na}^{+}$channel expression has been reported.

The movement of different ions through the cell membrane shapes the AP, organizing it in well-defined membrane depolarization and repolarization phases. The main difference between LV's and RV's AP is during phase 1, which corresponds to the synchronized opening of $\mathrm{K}^{+}$channels after the initial $\mathrm{Na}^{+}$inward current $[28,29]$. The RV has a deeper notch than the LV due to an increase in outward $\mathrm{K}^{+}$current density $[28,30,31]$. This increase is due to the larger amplitude of the transient outward current $\left(I_{\text {to }}\right)$ in the RV than in the LV [28, 30-32]. In some studies, no changes were observed in protein expression $[31,33]$ or in the inactivation constant $[30,32]$. APD differences between the LV and RV have been described in several species, with some studies finding more prolonged APD in the LV than the RV [29, 30, 32, 34-36], even in human hearts [37]. However, a lack of changes in APD was reported in Langendorff-perfused guinea pig hearts [38], and 2-9\% $\mathrm{RV}$ longer APD has been observed in dogs [26]. The $\mathrm{K}^{+}$repolarization currents can explain the shorter APD present in the RV. The RV's steeper repolarization phase's significant contribution is partially due to a higher density in the RV of the slowly activating component $\left(I_{\mathrm{Ks}}\right)$ of the delayed rectifier $K 1$ current [32]. In contrast, a rapidly activating component $\left(I_{\mathrm{Kr}}\right)$, the inward rectifier current $\left(I_{\mathrm{K} 1}\right)$, and the sustained current $\left(I_{\mathrm{SS}}\right)$ do not show changes in expression, density, or inactivation [29-33]. The ATP-activated $\mathrm{K}^{+}$current $\left(I_{\text {KATP }}\right)$ has been identified as a determinant factor of APD in ischemia, and its expression is higher in the LV than in the RV [38].

Changes in AP duration and shape may be considered since the cardiac AP's immediate consequence is the generation of an intracellular $\mathrm{Ca}^{2+}$ transient and differences observed between the APs of the LV and RV may influence intracellular $\mathrm{Ca}^{2+}$ dynamics. The initial membrane depolarization triggers the activation of L-type $\mathrm{Ca}^{2+}$ channels (LTCC), allowing an inward current of $\mathrm{Ca}^{2+}$, which, in turn, promotes the release of $\mathrm{Ca}^{2+}$ from the SR through the ryanodine receptors (RyR) by CICR, originating the $\mathrm{Ca}^{2+}$ transient [24]. Figure 1 shows the main differences between the RV and $\mathrm{LV}$ in the $\mathrm{Ca}^{2+}$ transient.

The link between the initial membrane depolarization and the $\mathrm{Ca}^{2+}$ transient is the LTCC. There is a clear difference between the AP in both ventricles; however, the initial phase of the $\mathrm{Ca}^{2+}$ transient is not affected by these changes. Indeed, while some reports show an increase in LTCC protein expression in the RV [27], others report unchanged gene expression between ventricles [29]. Moreover, the $\mathrm{Ca}^{2+}$ currents $\left(I_{\mathrm{Ca}}\right)$ do not show differences between ventricles [29].

Regarding RyR, there are no differences in $\mathrm{Ca}^{2+}$ concentration for half-maximal activation, the Hill coefficient, caffeine-sensitive ryanodine binding, or current density [39]. However, there are discrepancies in RyR expression in the RV, since some studies show unchanged protein expression, while others refer to lower expression [40]. More studies will be required to clarify these discrepancies.

At rest, there is no difference in diastolic $\mathrm{Ca}^{2+}$ between the right and left ventricles [29, 41]. However, although it seems that RyR expression and function are unchanged, it has been reported an increase in $\mathrm{Ca}^{2+}$ transient amplitude during systole in the $\operatorname{LV}[29,42]$, indicating a major $\mathrm{Ca}^{2+}$ release by the SR due to primary $\mathrm{Ca}^{2+}$ content [42]. A higher contraction force [36] and greater sarcomere shortening have been found in the LV than in the RV $[29,36,41,43]$, which coincides with the increase in the transient amplitude since the more significant the $\mathrm{Ca}^{2+}$ release, the greater the contraction force. However, two previous studies found no changes 
TABle 1: Physiological differences between ventricles in myocyte function.

\begin{tabular}{|c|c|c|c|c|c|}
\hline Process & Component & Level & $\begin{array}{c}\text { RV change } \\
\text { (Compared to LV) }\end{array}$ & Model & Reference \\
\hline \multirow{17}{*}{ Action potential } & \multirow{4}{*}{$\mathrm{INa}$} & Density & Lower & Dog & \multirow{4}{*}[26]{} \\
\hline & & $\begin{array}{c}\text { Expression (SCN5A,SCN1B } \\
\text { and } 4 \mathrm{~B})\end{array}$ & NC & Dog & \\
\hline & & Steady-state inactivation & Higher & Dog & \\
\hline & & Recovery from inactivation & Higher & Dog & \\
\hline & \multirow[t]{2}{*}{ AP } & \multirow[t]{2}{*}{ Duration } & Higher & $\begin{array}{l}\text { Human, Dog, Rat, Mice, } \\
\text { Human }\end{array}$ & {$[29,30,32,34-37]$} \\
\hline & & & $\mathrm{NC}$ & Guinea pig & {$[38]$} \\
\hline & \multirow{3}{*}{ Ito } & Current & Higher & Dog, Mice, Rat, Dog & {$[28,30-32]$} \\
\hline & & Expression & NC & Rabbit, Mice & {$[31,33]$} \\
\hline & & Inactivation constant & NC & Dog, Dog & {$[30,32]$} \\
\hline & $\mathrm{ICa}$ & Current & NC & Mice & {$[29]$} \\
\hline & \multirow{2}{*}{ IKs } & Density & Higher & Dog & {$[32]$} \\
\hline & & Expression & $\mathrm{NC}$ & Rabbit & [33] \\
\hline & $\mathrm{IKr}$ & Density & NC & Dog & {$[32]$} \\
\hline & \multirow{2}{*}{ IK1 } & Expression & NC & Mice, Dog & {$[30,31]$} \\
\hline & & Density & NC & Mice & [29] \\
\hline & ISS & Density & $\mathrm{NC}$ & Dog, Mice & {$[30,31]$} \\
\hline & IKATP & Expression & Lower & Guinea pig & {$[38]$} \\
\hline \multirow{13}{*}{ CIRC } & \multirow{3}{*}{ LTCC } & \multirow{2}{*}{ Expression } & Higher & Rabbit & [27] \\
\hline & & & $\mathrm{NC}$ & Mice & [29] \\
\hline & & Current & NC & Mice & [29] \\
\hline & \multirow{7}{*}{$\mathrm{Ca}^{2+}$ transient } & Activity & NC & Human & [39] \\
\hline & & Sensitivity & NC & Human & [39] \\
\hline & & Density & NC & Human & [39] \\
\hline & & \multirow{2}{*}{ Expression } & $\mathrm{NC}$ & Rabbit, Human & {$[27,154]$} \\
\hline & & & Lower & Dog & {$[40]$} \\
\hline & & Amplitude & Lower & Rat, Mice & {$[29,42]$} \\
\hline & & Time to decay & Higher & Rat & {$[36]$} \\
\hline & \multirow{2}{*}{ SR } & Volume & NC & Pig & {$[54]$} \\
\hline & & $\mathrm{Ca}^{2+}$ load & Lower & Rat & {$[42]$} \\
\hline & Diastolic $\mathrm{Ca}^{2+}$ & Level & NC & Mice, Rat & {$[29,41]$} \\
\hline \multirow{11}{*}{ Cell contraction } & \multicolumn{2}{|c|}{ Contraction force } & Lower & Dog & {$[36]$} \\
\hline & \multicolumn{2}{|c|}{ Sarcomere shortening } & Lower & Rat, Mice, Dog, Rat & {$[29,36,41,43]$} \\
\hline & Troponin I & Phosphorylation & NC & Mice & {$[46]$} \\
\hline & Troponin $\mathrm{T}$ & Phosphorylation & $\mathrm{NC}$ & Mice & [46] \\
\hline & MyBP-C & Phosphorylation & NC & Mice & [46] \\
\hline & MRLC & Phosphorylation & NC & Mice & {$[46]$} \\
\hline & $\begin{array}{l}\text { Actin-Myosin } \\
\text { binding }\end{array}$ & Mobility & Lower & Mice, Rabbit & {$[44,45]$} \\
\hline & \multicolumn{2}{|c|}{ Maximal shortening velocity } & Lower & Mice & {$[29]$} \\
\hline & \multicolumn{2}{|c|}{ Myofilaments $\mathrm{Ca}^{2+}$ sensitivity } & Lower & Rat, Mice & {$[46-48]$} \\
\hline & \multicolumn{2}{|c|}{ Myosine ATPase activity } & Higher & Rat, Rat & {$[49,50]$} \\
\hline & $\begin{array}{l}\text { Myosine heavy } \\
\text { chain }\end{array}$ & Alfa: beta proportion & Higher & Rat & [49] \\
\hline
\end{tabular}


TABLE 1: Continued.

\begin{tabular}{|c|c|c|c|c|c|}
\hline Process & Component & Level & $\begin{array}{c}\text { RV change } \\
\text { (Compared to LV) }\end{array}$ & Model & Reference \\
\hline \multirow{11}{*}{ Cell relaxation } & \multirow{7}{*}{ SERCA } & \multirow{3}{*}{ Activity } & Lower & Rat, Rat & {$[41,42]$} \\
\hline & & & Higher & Rat & {$[36]$} \\
\hline & & & NC & Mice & [29] \\
\hline & & \multirow{2}{*}{ Expression } & Lower & Rat & {$[41]$} \\
\hline & & & NC & Rat, Rabbit & {$[27,42]$} \\
\hline & & Phosphorylation & Lower & Rat & {$[41]$} \\
\hline & & Affinity to $\mathrm{Ca}^{2+}$ & Lower & Rat & {$[41]$} \\
\hline & \multirow{2}{*}{ SERCA-PBL } & Ratio & NC & Rat & \multirow{2}{*}[41]{} \\
\hline & & Stability complex & Higher & Rat & \\
\hline & \multirow[b]{2}{*}{ NCX } & Expression & Higher & Rabbit & [27] \\
\hline & & $\begin{array}{c}\text { Rest-potentiation } \\
\text { phenomenon }\end{array}$ & Higher & Rat, Mice & {$[29,36]$} \\
\hline \multirow{8}{*}{ Cell energetics } & \multirow{2}{*}{$\begin{array}{l}\text { Mitochondria } \\
\text { respiration }\end{array}$} & Expression & NC & Rat & {$[53]$} \\
\hline & & Activity & NC & Dog & {$[52]$} \\
\hline & $\begin{array}{l}\text { Oxidative } \\
\text { metabolism }\end{array}$ & Expression & NC & Rat & {$[53]$} \\
\hline & Fatty acid oxidation & Expression & NC & Rat & [53] \\
\hline & Rate of oxidation & Activity & Lower & Rat & {$[53]$} \\
\hline & \multirow{3}{*}{$\begin{array}{l}\text { Mitochondria } \\
\text { content }\end{array}$} & Citrate synthase activity & Lower & Rat & {$[53]$} \\
\hline & & $\begin{array}{l}\text { Mitochondria-myofibrils } \\
\text { ratio }\end{array}$ & Lower & Pig & {$[54]$} \\
\hline & & Mitochondria volume & NC & Pig & [54] \\
\hline
\end{tabular}

NC: no change.

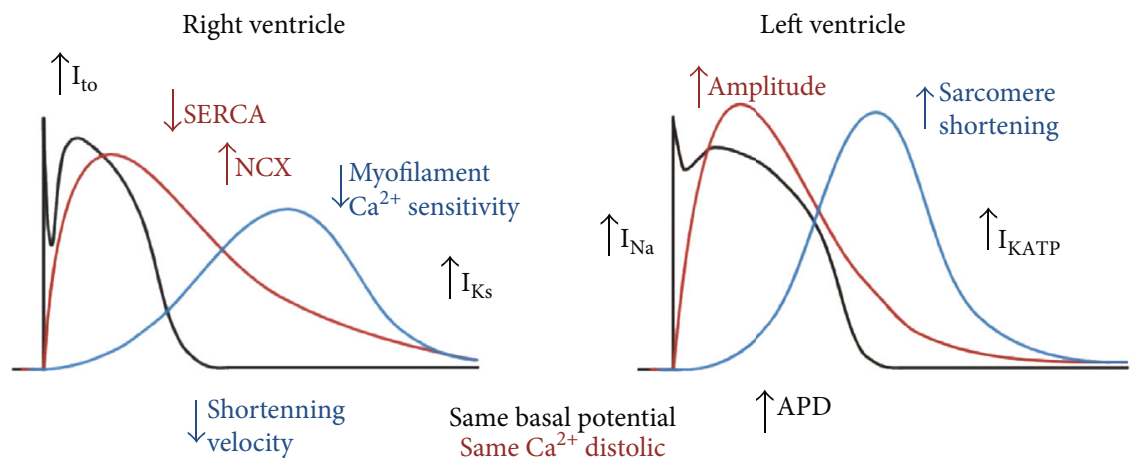

FIGURE 1: Physiological differences in excitation-contraction coupling between ventricles. Black lines, letters and arrows represent the action potential; red lines, letters and arrows represent $\mathrm{Ca}^{2+}$ transient; blue line, letters and arrows represent cellular shortening. $I_{\text {to }}$ : transient outward current; $I_{\mathrm{Ks}}$ : slowly activating component; $I_{\mathrm{Na}}$ : sodium inward current; $I_{\mathrm{KATP}}$ : ATP-activated $\mathrm{K}^{+}$current; ADP: action potential duration; SERCA: sarcoendoplasmic reticulum $\mathrm{Ca}^{2+}$ ATPase; NCX: sodium-calcium exchanger. The figure was created with BioRender.com.

in sarcomere shortening in rats $[41,42]$. Furthermore, at the molecular level, actin interacts differently with myosin crossbridges in the LV, allowing greater mobility of actin monomers and, hence, greater contractility [44, 45], without changes in troponin $\mathrm{I}$ and $\mathrm{T}$, myosin-binding protein $\mathrm{C}$ (MyBP-C), or the myosin regulatory light chain phosphorylation, between LV and RV [46]. On the other hand, the maximal shortening velocity is also slower in RV myocytes [29], which is related to decreased $\mathrm{Ca}^{2+}$ sensitivity in RV myofilaments [46-48]. However, greater myosin ATPase activity $[49,50]$ and a faster cellular contraction in the RV have also been reported due to a larger proportion of heavy $\alpha$-chaincontaining myosin isozyme in the RV compared to the $\mathrm{LV}$, which has a larger proportion of the slower $\beta$-chain [49]. All the expression changes between ventricles are summarized in Table 1. 
For relaxation to occur during diastole, intracellular $\mathrm{Ca}^{2+}$ must decline, and the sarco/endoplasmic reticulum $\mathrm{Ca}^{2+}$ ATPase (SERCA) pump is the primary removal mechanism [24]. As illustrated in Figure 1, a more prolonged $\mathrm{Ca}^{2+}$ transient has been reported in RV myocytes than in LV myocytes $[41,42]$, accompanied by decreased SERCA activity $[41,42]$ and expression, as well as affinity to $\mathrm{Ca}^{2+}$ in the RV [41]. Phospholamban (PLB) is a critical SERCA inhibitor, but PLB phosphorylation relieves SERCA of its inhibition [51]. A previous study found that LV and RV present similar SERCA/PLB ratios but the RV's SERCA-PLB complex is more stable than in LV [41]. The decreased SERCA activity in $\mathrm{RV}$ myocytes may allow more active participation of other $\mathrm{Ca}^{2+}$ removal mechanisms, leading to lower $\mathrm{Ca}^{2+}$ availability in the SR. This phenomenon might explain the decreased transient amplitudes and SR content [42] observed in RV myocytes when compared to LV myocytes. However, there are some discrepancies since faster relaxation has been reported in the RV [36] than in the LV, as well as no differences in SERCA and PBL activity [29] and expression $[27,42]$ between LV and RV.

Another important $\mathrm{Ca}^{2+}$ removal mechanism in cardiomyocytes is the $\mathrm{Na}^{+} / \mathrm{Ca}^{2+}$ exchanger (NCX). Higher NCX protein expression has been found in RV than in LV [27] (Table 1), which might also explain the decreased SR $\mathrm{Ca}^{2+}$ availability, resulting in a decreased $\mathrm{Ca}^{2+}$ transient amplitude without changes in SERCA activity. However, regardless of its expression, NCX is more active in LV than in RV [36], promoting $\mathrm{Ca}^{2+}$ overload in the $\mathrm{SR}$ during the restpotentiation phenomenon, which is more prominent in the LV than in the RV [36]; thus, there are differences in the balance between $\mathrm{Ca}^{2+}$ entry and SR loading in the right and left ventricles. Notably, the mitochondrial $\mathrm{Ca}^{2+}$ uniporter and mitochondrial NCX contribute to $\mathrm{Ca}^{2+}$ handling in cardiac cells [25], but the function and expression of these systems remain unknown in RV cardiomyocytes.

Otherwise, cell relaxation is a high energy-dependent process. $\mathrm{Ca}^{2+}$ removal against its concentration gradient by SERCA and the detachment of myosin heads from actin require an adequate ATP supply [24]. Mitochondria are the organelle responsible for energy production in ATP form. There is no change in respiratory components, oxidative metabolism, fatty acid oxidation, or mitochondria respiration between the right and left ventricles [52, 53]. However, the LV has a higher rate of oxidation and mitochondrial membrane potential. This finding has been understood as higher mitochondrial content, supported by a higher citrate synthase activity [53], a higher mitochondria-myofibril ratio [54], and higher nitrosylated protein content in LV than in RV [53]. The mechanism that induces differential levels of mitochondrial biogenesis between the LV and RV is entirely unknown and could be a fertile research area in the future.

\section{Distinctions between Right and Left Ventricle Dysfunction}

In the vascular system, the RV has not received much research attention since 1943, when cauterization of the RV free wall in canine hearts did not change venous pressure
[55]. Furthermore, the LV is more severely affected than the RV in heart disease. However, the medical field's perception of the RV is changing from it being considered unimportant to it being an essential component of normal hemodynamics [56]. More recently, significant differences have been recognized in right and left heart failure progression [11]. Although changes in the left ventricles of failing hearts have been thoroughly described, the assumption that the same mechanism is involved in LV and RV failure has been challenged in recent decades. Physiological and structural differences between the two ventricles may explain the differences in the pathologies each ventricle faces, giving importance to underlying mechanisms that make them more susceptible or resistant to diverse insults.

3.1. Differences between Right and Left Ventricular Infarction. The compromised coronary artery predominantly determines the size and location of the infarction. Acute right ventricular infarction (RVMI) can occur when there is occlusion of the right coronary artery (RCA), proximally to the takeoff of RV branches [57]. The RVMI is an infrequent event, occurring in one-third to one-half of patients presenting with inferior myocardial infarction; very rarely, it can occur in isolation [58].

The term RV infarction may be somewhat misleading since acute RV ischemic dysfunction frequently has a faster recovery than $L V$ infarction. Indeed, there is a deep contrast between the effects of ischemia and reperfusion in RV and in $\mathrm{LV}$, in which prolonged ischemia often leads to myocardial infarction. Levin and Goldstein proposed diverse reasons to explain LV's lower vulnerability to infarction. First, oxygen demand is undoubtedly lower in the RV than in the LV, because of its much smaller muscle mass and lower afterload. Second, in the absence of severe RV hypertrophy or pressure overload, the coronary artery flow in the RV is given in both diastole and systole. Third, chronic RV failure attributable to $\mathrm{RV}$ myocardial infarction is infrequent. Fourth, there is greater availability of blood perfusion in the RV through the collateral flow from the left to right coronary arteries [59]. However, Heresi et al. used a sensitive assay to measure cardiac troponin I (cTnI), a myocardial infarction biomarker, and found a significant positive association between cTnI and a more severe PAH and worse clinical outcomes in patients with $\mathrm{PAH}$ [60], suggesting that the susceptibility of the RV to ischemic events is not completely understood.

\subsection{Differential Mechanisms of Right versus Left Pathological} Remodeling. Cardiac hypertrophy is defined as an increase in cardiac mass manifested by increasing size, as well as morphological and functional alterations attributed to a physiological or pathological stimulus. Physical exercise is an example of a physiological stimulus, while a pathological stimulus is found in hypertension, diabetes, myocardial ischemia, and other conditions [61]. Cardiac hypertrophy is considered an adaptive response to increased activity or functional overload, and it is classified as eccentric or concentric. An increase in preload due to high blood volumes reaching the heart, usually observed in aortic regurgitation or endurance exercise, leads to eccentric hypertrophy. This 
represents a serial addition of sarcomeres, which increases of the ventricular chamber volume and the wall thickness. A higher afterload due to pressure overload in the ventricle leads to concentric hypertrophy. This represents a parallel addition of sarcomeres, which increases myocardial thickness and reduces the diameter of the ventricular chamber [61].

Concentric hypertrophy is generally accompanied by remodeling to adapt to pressure overload and maintain a stable cardiac output. Next, remodeling progresses from an adaptive to a maladaptive phenotype, with altered contractility that leads to cardiac failure [62]. Differences in LV and RV responses to pressure overload have been described $[63,64]$. The compensatory remodeling is restricted in RV versus LV. Inhibition of nitric oxide with L-NAME generates LV and RV hypertrophy, but the RV responds with dilation, dysfunction, and an increase in reactive oxygen species (ROS), which causes the inhibition of hypoxia-inducible factor $1-\alpha$ (HIF1 $\alpha$ ) and the suppression of angiogenesis, inducing chronic ischemia in the RV $[64,65]$. Moreover, a reduction in superoxide dismutase in the RV versus its increase in the LV has been observed [64]. Additionally, pressure overload in the RV in pulmonary artery banding (PAB) models leads to higher mortality and oxidative stress than pressure overload in the $\mathrm{LV}$ by aortic constriction. PAB models also produce more elevated hypoxia in the RV after surgery, with less capillary density and ischemia [66].

Furthermore, mechanical stress on the ventricular wall due to pressure overload stimulates fibroblasts to differentiate into myofibroblasts that produce type II and III collagen in the LV and RV, contributing to cardiac failure $[67,68]$. However, differences in the distribution of extracellular matrix (ECM) protein and metalloproteinases in the LV and RV may be explained by a further ECM degradation pattern between ventricles [69], which could explain why effective antifibrotic therapies in LV failure are not effective in RV failure [70]. On the other hand, in chronic thromboembolic pulmonary hypertension, to adjust the RV afterload and wall stress, RV pathological remodeling and wall hypertrophy occur [71], and ECM biomarkers, such as matrix metalloproteinases 2 and 9, decrease, while tissue inhibitor of metalloproteinases-1 (TIMP-1) increases significantly [72]. Notably, treatment with a massive pulmonary embolus is applied to relieve the RV afterload (e.g., pulmonary artery endarterectomy, systemic thrombolytics, or percutaneous intervention), resulting in significant regression of pathological remodeling and RV hypertrophy [71].

Studies have shown shared molecular pathways to hypertrophy and fibrosis between the LV and RV, such as TGF- $\beta$, Rho-ROCK, and MAPKs. However, differences in signaling have been observed in MAPKs [61, 65]. Phosphorylated p38 (p-p38) MAPK increases in RV fibroblasts and mediates fibrosis induced by TGF- $\beta$ and ventricular dysfunction; however, hypertrophy and changes in proinflammatory genes are not mediated by p-p38 MAPK [73]. In the LV, the role of p38 MAPK, specifically p38 $\alpha$, has been also described as a mediator of fibrosis and hypertrophy, but conversely, interleukin6 is involved as a probable pathway to induce hypertrophy [74]. Furthermore, while the apelin receptor (APJ) partici- pates in hypertrophy induced by pressure overload and apelin prevents hypertrophy in the LV [75-77], the role of APJ in RV has not been elucidated [78].

Difference between RV and LV responses also depends on the stimulus. ROCK signaling mediates hypertrophy induced by metabolic alterations in the LV and by hypoxia in the RV [61], but also, it induces hypertrophy in the LV and RV in pressure overload models, inducing p-ERK1/2 and GATA4 $[66,79]$. Studies have demonstrated angiotensin II's role through AT1R in LV hypertrophy due to pressure overload [80-82], whereas an increase in mRNA levels of angiotensin in the monocrotaline (MCT) model has been reported [83]; however, its role in RV has not been fully demonstrated. Angiotensin II is also involved in the induction of autophagy [81]. The role of autophagy in cardiac hypertrophy is controversial; however, basal autophagy would be essential for the preservation of cellular homeostasis, whereas excessive autophagy or its inhibition could aggravate hypertrophy. In different models, such as LV hypertrophy induced by pressure overload or metabolic dysfunction $[84,85]$ and RV hypertrophy induced by monocrotaline-induced pulmonary arterial hypertension (MCT-PAH) or hypoxia [86, 87], hypertrophy would be mediated by the induction of autophagy, while its inhibition could prevent hypertrophy [85].

On the other hand, activation of proteasome has been observed in LVs exposed to pressure overload, which produces hypertrophy [88], similar to findings obtained in RVs [89]. However, another study performed using the pressure overload model in RVs observed a reduction in proteasome activity [90]; this study was conducted 8-10 days after surgery contrarily to the previous study performed three weeks after surgery [89].

Epigenetic mechanisms have also been identified in cardiac hypertrophy. Class I histone deacetylase inhibitors (HDACs) induce hypertrophy in the LV and RV [91, 92], whereas class IIa HDACs prevent hypertrophy [91, 93]. Unlike findings in the LV [94], inhibitors of HDACs aggravate RV hypertrophy induced by pressure overload [93, 95]. Therefore, further studies are needed to better understand hypertrophy mechanisms in the LV and, mainly, in the RV.

The inflammatory response also plays an essential role in heart failure progression by the activation of proinflammatory cytokines [96]. The increase in inflammatory mediators that can interfere with cardiac contractility and remodeling in PAH correlates to RV dysfunction [97]. While the effects of anti-inflammatory therapies in LV failure are unclear $[98,99]$, they might be useful in preventing RV failure since perivascular inflammation triggers $\mathrm{RV}$ inflammation in a vicious cycle that leads to RV failure [97].

\subsection{An Overview of the Similarities and Differences between} Right and Left Ventricular Failure. The increase in LV afterload by an overload of pressure or volume is considered a determining cause of left heart failure (LHF). In contrast, pulmonary hypertension, pulmonary stenosis, chronic obstructive pulmonary disease, and tricuspid valve pathology produce similar consequences on the right side, inducing right heart failure (RHF) [100-102]. RHF could be acute or chronic. Acute RHF is caused by a suddenly increased RV 
afterload due to hypoxia or a pulmonary embolus [102, 103] or decreased RV contractility in RV ischemia, myocarditis, or postcardiotomy shock [104]. On the other hand, chronic RHF results from the gradual increases in RV afterload produced by pulmonary hypertension $[101,102]$, which promotes cardiac remodeling with increased RV mass, fibrosis, and hypertrophy of cardiomyocytes, analogous to the remodeling observed in LHF [105].

As a further example of the interconnection between both ventricles, the prevalence of RV dysfunction increases with LHF progression [106], and RV function and RV-pulmonary artery coupling fail progressively across HF stages [107]. In a community-based cohort study, subclinical RV dysfunction was present in nearly $20 \%$ of elderly people and was associated with common HF risk factors. Among people without HF, lower RVEF was associated with HF and death independent of LVEF or N-terminal pro-brain natriuretic peptide (pro-BNP) [107], suggesting that RV dysfunction plays a crucial and underestimated role in HF progression. RV dysfunction was observed in $48 \%$ [108] and $33 \%$ [109] of heart failure with reduced ejection fraction (HFrEF) and with preserved ejection fraction (HFpEF) patients, respectively, and HFpEF patients displayed greater right-sided chamber enlargement, higher RV diastolic pressure, and more severe contractile dysfunction compared to controls [109].

Furthermore, in patients with LHF, the development of pulmonary hypertension and RV dysfunction is common, and they play an essential role in disease progression, morbidity, and mortality. The diagnosis of pulmonary hypertension aggravates the prognosis in HFpEF and HFrEF patients, and pulmonary hypertension is observed in approximately $75 \%$ of patients with HFpEF. Thereby, this prevalence is higher than in patients with $\operatorname{HFrEF}[100,110]$. In a large community-based prospective cohort of 1,049 subjects with $\mathrm{HF}$, pulmonary hypertension was described as an independent and strong predictor of mortality [110]. Pulmonary hypertension was also defined as a decisive factor in posttransplant mortality because the significantly elevated levels of pulmonary vascular resistance in the postoperative period to which the donor's heart is exposed could trigger RV dysfunction [111].

The requirements of oxygen, glucose absorption, and the glycolytic rate increase in both the LV and RV, reducing fatty acid metabolism [112]. An increased hemodynamic load causes the activation of a pattern of early response or the immediate-early genes $c$-fos and $c$-jun, followed by the induction of a "fetal gene program" for the sarcomeric proteins and natriuretic peptides: atrial natriuretic peptide (ANP) and BNP, whose expression is observed also in both ventricles [66, 113].

Mitochondrial dysfunction is an important and crucial mechanism in the development of heart failure [114]. Hypertrophy triggers the Warburg effect in the RV, shifting metabolism from aerobic to anaerobic, showing a decrease in glucose oxidation and increased uncoupled glycolysis and glucose uptake [115], as well as decreasing mitochondrial membrane potential and compromising ATP production [116]. Therefore, protecting mitochondrial function and metabolism has shown positive results in preserving RV function. On the other hand, glutamine antagonist [117] and sodium-glucose cotransporter 2 (SGLT2) inhibitors [118] positively affect cardiac performance, RV hypertrophy, and survival. Regarding fatty acid oxidation (FAO), the information is controversial since RV function improvement has been observed following FAO inhibition [119] and stimulation [120]. Improvement in mitochondrial fragility and membrane potential by activating SIRT3 through stilbene resveratrol administration improves $\mathrm{RV}$ function and decreases fibrosis and hypertrophy $[43,121]$.

In LV and RV failure, alterations in ECC and relaxation are observed. In the LV, diastolic dysfunction with a slower contraction-relaxation kinetic is produced, as well as loss of T-tubules, reduced SR density, and altered $\mathrm{Ca}^{2+}$ release from the SR. These changes were also described in RV failure, where loss of T-tubules, smaller and slower intracellular $\mathrm{Ca}^{2+}$ transients, reduction and disorganization of the RyR2 network, and reduction of SERCA have been observed in severe hypertrophy caused by MCT-PAH [62]. However, it has been reported that remodeling of the LV wall, which causes diastolic dysfunction, is compensated by an increase in the contraction-relaxation kinetic in cardiomyocytes [122]. PAH-RV treated with resveratrol significantly improves cell relaxation dynamics by enhancing SERCA activity and maintaining the mitochondrial energy supply [121].

The role of $\mathrm{Ca}^{2+}$ signaling has been well demonstrated. $\mathrm{Ca}^{2+}$ binds to calmodulin (CaM), which activates calcineurin, a phosphatase that dephosphorylates NFAT in the cytosol, allowing its nuclear translocation to regulate the expression of prohypertrophic genes, such as the $\beta$-myosin heavy chain ( $\beta$-MHC). Additionally, $\mathrm{Ca}^{2+} / \mathrm{CaM}$ activates $\mathrm{Ca}^{2+} / \mathrm{CaM}$ kinase II (CaMKII), which induces the nuclear export of histone deacetylase 5 (HDAC5), derepressing the prohypertrophic transcription factor Mef2 [123]. Mef2 has been implicated in the underlying mechanisms that cause a switch from compensated to decompensated hypertrophy in the RV; Mef2 increases in compensated hypertrophy and decreases during decompensation [124]. In the LV, the role of TGF- $\beta$ and its signaling pathway as a molecular switch has also been reported [65].

\section{A Clinical and Experimental Therapeutic Approach to RV Dysfunction}

As mentioned previously, patients with PAH develop RV remodeling due to the progressive increase in pulmonary vascular resistance and pulmonary artery pressure, leading to RV failure. Although RV failure is the leading cause of death in $\mathrm{PAH}$ patients, most PAH treatments (e.g., prostaglandin analogs, $\mathrm{Ca}^{2+}$-antagonists, endothelin receptor antagonists, and nitric oxide) target vascular abnormalities. Therefore, the amelioration of RV remodeling and dysfunction may represent an essential aspect of PAH therapy, but unfortunately, current therapies do not improve RV function.

Under the experimental therapeutic side, different research groups have focused on observing the effects of $\mathrm{PAH}$ treatment directly on RV function, mostly using the in vivo induction of $\mathrm{PAH}$ by $\mathrm{MCT}, \mathrm{PAB}$, or hypoxia. Three 
main action mechanisms are identified. The first and most common mechanism is the blocking of surface receptor signaling, in which the compounds tend to act on multiple receptors. Second, the reduction of cytosolic ROS production by trapidil and pterostilbene at different levels of signaling prevents RV remodeling. The third mechanism is the preservation of the metabolic capacity of the cell, where ursolic acid prevents lipotoxicity, while CsA and RES preserve mitochondrial function. Table 2 and Figure 2 summarize the effects of different $\mathrm{PAH}$ treatments on $\mathrm{RV}$ remodeling and protection. Using recombinant human neuregulin (rhNRG-1), Adão et al. observed attenuation in the increased PLB phosphorylation and decreased mRNA expression of Colla2, Col3a1, and ACTA1 caused by MCT-PAH in Wistar rats, as well as decreased passive tension in the rats' isolated RV cardiomyocytes [125]. Treatment with rhNGR-1 also decreased the Fulton index scores, the cardiomyocyte cross-sectional area, and fibrosis caused by PAB-induced PAH in Wistar rats [125]. During treatment of PAH caused by MCT in SpragueDawley rats, An et al. [126] observed that a maxingxiongting mixture (MXXTM, an effective Chinese medicine compound prescribed for pulmonary hypertension) reduced the protein expression of RhoA and ROCK II, suggesting that it might improve RV hypertrophy by inhibiting the Rho-kinase signaling pathway in the treatment of pulmonary hypertension. Using a hypoxia-induced $\mathrm{PAH}$ in vivo model, Dang et al. observed decreased myocardial and RV hypertrophy and collagen deposition, as well as the downregulation of collagen I and III genes and ACE, AngII, and AT1R proteins, when Sprague-Dawley rats were treated with Tsantan Sumtang, a traditional and commonly prescribed Tibetan medicine. Treatment with Tsantan Sumtang attenuated RV remodeling and fibrosis, likely through disruption of the ACE-AngIIAT1R equilibrium in the RV [127].

After treating of PAH caused by an MCT in vivo model with ursolic acid, Gao et al. observed the preservation of RV function and the attenuation of hypertrophy indexes. The expression of Col1a1, Col3a1, TGF $\beta 1$, and Bax, as well as fibrosis and apoptosis markers, also decreased [128]. Similarly, when using resveratrol, a phenolic compound with known cardioprotective effects, in an MCT-PAH in vivo model, Vázquez-Garza et al. observed improved RV function measured by tricuspid annular plane systolic excursion (TAPSE) technique and RV free wall thickness and contractility and decreased RV fibrosis and cardiomyocyte area and volume, caused by the low mRNA expression of BNP, Tnnc1, and Colla1, as well as increased IL-10 and SIRT1 mRNA levels [43]. These mRNA markers were also decreased after using nintedanib to treat PAH in a SU5416+hypoxia in vivo model. Rol et al. observed a decrease in RV hypertrophy and collagen content, accompanied by reduced mRNA levels of Colla1, BNP, and OPN [129]. Furthermore, Leong et al. observed reduced cardiac remodeling biomarker BNP mRNA levels and serum-NT-pro-BNP levels after treating Wistar-Imamichi rats with imatinib and sunitinib in an MCT-PAH in vivo model [130].

On the other hand, in a PAB in vivo model, Rai et al. observed the preservation of RV function by the attenuation of the increase in RV end-diastolic/systolic volume and colla- gen content after $\mathrm{C} 57 \mathrm{Bl} / 6 \mathrm{~J}$ mice were treated with riociguat or sildenafil [131]. These compounds also reduced collagen production and secretion and the phosphorylation of Smad2 and Smad3 proteins when used to treat RV cardiac fibroblast stimulated with TGF $\beta 1$ in vitro. Therapy with macitentan also improved RV function and hypertrophy caused by $\mathrm{PAB}$ in Wistar-Tokyo rats [132].

In a hypoxia-induced PAH model, Schmuck et al. observed that mesenchymal stem cells had a protective effect on RV function. A reduction in RV hypertrophy was observed, with an attenuated RV stroke volume and cardiac output, maintained RV contractility, reduced RV collagen content, and slowed cardiomyocyte enlargement [133].

Poststress conditions could increase ROS in the RV, a determinant factor in many diseases' progression and severity. Pterostilbene complexed with hydroxypropyl- $\beta$-cyclodextrin $(\mathrm{HP} \beta \mathrm{CD})$ to treat $\mathrm{PAH}$ induced by MCT in vivo, Lacerda et al. observed an increase in GSH concentrations and GSH/GSSG ratio, accompanied by restored glutathione reductase, glutathione-S-transferase, and glutaredoxin enzyme activity [134]. This treatment also increased the expression of SERCA. Similarly, using trapidil to treat PAH in a MCT in vivo model, Türck et al. observed increased GSH/total glutathione ratio, decreased NADPH oxidase activity, and increased RV SERCA and RyR protein content [135]. The results of these studies suggest that oxidative stress and improving the $\mathrm{RV}^{\prime} \mathrm{s} \mathrm{Ca}^{2+}$ handling mechanisms may represent valuable targets to treat $\mathrm{PAH}$.

As mitochondria play a key role in heart pathophysiology, Lee et al. investigated the effect of cyclosporine A (CsA) in MCT-PAH in vivo [114]. Despite the increase in $\mathrm{RV}$ mass, CsA prevented the mitochondrial disruption caused by MCT and attenuated the increases in apoptotic protein Casp3 and Apoptosis-Inducing Factor (AIF) levels. Similarly, Bernal-Ramírez et al. [121] showed that resveratrol treatment in MC-induced PAH rat model avoids mitochondrial permeability and transition pore formation by decreasing cyclophilin D (CypD) hyperacetylation via SIRT3 activation. The combinatorial treatment with macitentan and tadalafil used by Mamazhakypov et al. in Wistar-Kyoto rats with $\mathrm{PAH}$ induced by SU5416+hypoxia improved RV function and decreased the expression of hypertrophy A-type natriuretic peptide precursor (NPPA), B-type natriuretic peptide precursor (NPPB), and fibrosis Colla1 markers [132]. The results of these studies suggest that the use of combinatorial treatments or the addition of an RV-targeted therapy, such as CsA, might be a new therapeutic strategy in the treatment of PAH.

Various clinical trials have been conducted to better understand or more effectively treat PAH. However, most of them managed cardiac improvement secondary to reduced pulmonary artery pressure instead of managing it as a primary objective. Clinical trials aimed at RV function have studied functional and structural improvement by measuring various parameters. Table 3 summarizes the available clinical trial results with measures focused on RV function through RVEF, RV end-diastolic, end-systolic volume (RVEDV and RVESV), mass, longitudinal strain, TAPSE, or Tei index parameters. 
TABLE 2: Treatment of PAH focused on RV remodeling and protection of its function.

\begin{tabular}{|c|c|c|c|c|}
\hline Biological subject & Treatment & $\begin{array}{l}\text { Experimental } \\
\text { model }\end{array}$ & Effect on RV compared with the model group & Reference \\
\hline $\begin{array}{l}\text { Isolated skinned } \\
\text { cardiomyocytes } \\
\text { (Wistar rats) }\end{array}$ & $\begin{array}{l}\text { Recombinant human } \\
\text { neuregulin-1 (rhNRG-1) }\end{array}$ & MC-induced PAH & $\begin{array}{l}\text { Decreased RV isolated cardiomyocyte passive } \\
\text { tension }\end{array}$ & {$[125]$} \\
\hline \multirow[t]{2}{*}{ Wistar rats } & \multirow[t]{2}{*}{$\begin{array}{l}\text { Recombinant human } \\
\text { neuregulin-1 (rhNRG-1) }\end{array}$} & MC-induced PAH & $\begin{array}{c}\text { Attenuate the increase of phospholamban } \\
\text { phosphorylation } \\
\text { Attenuate the upregulated mRNA expression of } \\
\text { Colla2, Col3a1, and ACTA1 }\end{array}$ & \multirow[t]{2}{*}[125]{} \\
\hline & & $\begin{array}{l}\text { PAB-induced } \\
\text { pressure overload }\end{array}$ & $\begin{array}{l}\text { Decreased Fulton index, cardiomyocyte CSA, and } \\
\text { fibrosis }\end{array}$ & \\
\hline Sprague-Dawley rats & Maxingxiongting mixture & MC-induced PAH & $\begin{array}{l}\text { Attenuate the upregulated protein expression of } \\
\text { RhoA and ROCK II }\end{array}$ & {$[126]$} \\
\hline & & & $\begin{array}{c}\text { Decrease RVHI, RV/TL, myocardial hypertrophy, } \\
\text { and collagen deposition }\end{array}$ & \\
\hline Sprague-Dawley rats & Tsantan Sumtang & Hx-induced PAH & $\begin{array}{c}\text { Downregulate collagen I and III levels and } \\
\text { hydroxyproline content } \\
\text { Downregulated levels of ACE, AngII, and AT1R } \\
\text { proteins }\end{array}$ & {$[127]$} \\
\hline Sprague-Dawley rats & Ursolic acid & MC-induced PAH & $\begin{array}{c}\text { Higher TAPSE and PAT/PET } \\
\text { Prevented increase in RVSP } \\
\text { Attenuated the increase of RVHI, RV myocardial cell } \\
\text { size, and cross-sectional area } \\
\text { Attenuated the increased expression of Colla1, } \\
\text { Col3a1, TGF } \beta 1 \text {, and Bax }\end{array}$ & {$[128]$} \\
\hline Sprague-Dawley rats & Resveratrol & MC-induced PAH & $\begin{array}{c}\text { Improved TAPSE, RV free wall thickness, and } \\
\text { contractility } \\
\text { Decreased RV fibrosis and cardiomyocyte area and } \\
\text { volume } \\
\text { Decreased BNP, Tnnc1, and Colla1 mRNA levels } \\
\text { Increased IL-10 and SIRT1 mRNA levels }\end{array}$ & {$[43]$} \\
\hline Sprague-Dawley rats & Nintedanib & $\begin{array}{l}\text { SU5416+Hx- } \\
\text { induced PAH }\end{array}$ & $\begin{array}{c}\text { Decreased RV hypertrophy } \\
\text { Reduced RV total collagen content } \\
\text { Reduced Colla1, BNP, and OPN mRNA levels }\end{array}$ & [129] \\
\hline $\begin{array}{l}\text { Wistar-Imamichi } \\
\text { rats }\end{array}$ & Imatinib & MC-induced PAH & $\begin{array}{c}\text { Reduced RVH } \\
\text { Reduced RV BNP mRNA expression and } \\
\text { serum NT-pro-BNP levels }\end{array}$ & {$[130]$} \\
\hline \multirow{3}{*}{ C57Bl/6J mice } & Sunitinib & & $\begin{array}{c}\text { Reduced RVH } \\
\text { Reduced RV BNP mRNA expression and serum } \\
\text { NT-pro-BNP levels }\end{array}$ & \multirow{3}{*}[131]{} \\
\hline & Riociguat & $\begin{array}{l}\text { PAB-induced } \\
\text { pressure overload }\end{array}$ & $\begin{array}{c}\text { Attenuated the increase of RV end-diastolic/systolic } \\
\text { volume } \\
\text { Reduced RV collagen content }\end{array}$ & \\
\hline & Sildenafil & & $\begin{array}{c}\text { Attenuated the increase of RV end-diastolic/systolic } \\
\text { volume }\end{array}$ & \\
\hline Sprague-Dawley rats & Mesenchymal stem cells & $\begin{array}{l}\text { SU5416+Hx- } \\
\text { induced } \mathrm{PAH}\end{array}$ & $\begin{array}{c}\text { Reduced RV hypertrophy } \\
\text { Attenuated the reduction of RV stroke volume and } \\
\text { cardiac output } \\
\text { Maintained RV contractility } \\
\text { Reduced RV collagen content and cardiomyocyte } \\
\text { enlargement }\end{array}$ & [133] \\
\hline
\end{tabular}


TABLE 2: Continued.

\begin{tabular}{|c|c|c|c|c|}
\hline Biological subject & Treatment & $\begin{array}{l}\text { Experimental } \\
\text { model }\end{array}$ & Effect on RV compared with the model group & Reference \\
\hline \multirow{3}{*}{ Wistar-Kyoto rats } & Macitentan & $\begin{array}{l}\text { SU5416+Hx- } \\
\text { induced PAH }\end{array}$ & $\begin{array}{c}\text { Reduced RVSP, TPVR, and RV hypertrophy } \\
\text { Increased cardiac output, TAPSE, and RV dilatation } \\
\text { Attenuated the increase of NPPA and NPPB } \\
\text { expression } \\
\text { Attenuated the increase of Colla1 }\end{array}$ & \multirow[t]{3}{*}[132]{} \\
\hline & Tadalafil & & $\begin{array}{c}\text { Reduced RVSP, TPVR, and RV hypertrophy } \\
\text { Increased cardiac output, TAPSE, and RV dilatation } \\
\text { Attenuated the increase of NPPA and NPPB } \\
\text { expression } \\
\text { Attenuated the increase of Colla1 }\end{array}$ & \\
\hline & Macitentan+tadalafil & & $\begin{array}{c}\text { Reduced RVSP, TPVR, and RV hypertrophy } \\
\text { Increased cardiac output, TAPSE, and RV dilatation } \\
\text { Attenuated the increase of NPPA and NPPB } \\
\text { expression } \\
\text { Attenuated the increase of Colla1 and Col3a1 }\end{array}$ & \\
\hline Wistar rats & $\begin{array}{l}\text { Pterostilbene complexed with } \\
\text { HP } \beta \text { CD }\end{array}$ & MC-induced PAH & $\begin{array}{c}\text { Increased concentration of GSH and GSH/GSSG } \\
\text { ratio } \\
\text { Restored the activity of GSR, GST, and GRx } \\
\text { Reduced TBARS levels } \\
\text { Increased expression of SERCA }\end{array}$ & {$[134]$} \\
\hline Wistar rats & Trapidil & MC-induced PAH & $\begin{array}{c}\text { Increased GSH/total glutathione ratio } \\
\text { Decreased NADPH oxidase activity } \\
\text { Increased RV SERCA and ryanodine receptor } \\
\text { protein content }\end{array}$ & {$[135]$} \\
\hline Sprague-Dawley rats & Cyclosporine A & MC-induced PAH & $\begin{array}{c}\text { Increased RV mass } \\
\text { Prevented mitochondrial disruptions } \\
\text { Attenuated the increase of Casp3 and AIF protein } \\
\text { levels }\end{array}$ & {$[114]$} \\
\hline Sprague-Dawley rats & $17 \beta$-Estradiol & MC-induced PAH & $\begin{array}{l}\text { Reduced RV diameter, wall thickness, fibrosis, } \\
\text { RV/LV+IVS, and RV/BW ratio } \\
\text { Improvement of TAPSE, RVFAC, and RIMP } \\
\text { Decreased serum BNP levels }\end{array}$ & {$[155]$} \\
\hline
\end{tabular}

Among the therapeutic compounds studied for $\mathrm{PAH}$ treatment at clinical trials are anti-ischemic agents (e.g., trimetazidine and ranolazine), vasodilators (e.g., treprostinil, sildenafil, tadalafil, and riociguat), endothelin receptor antagonists (e.g., ambrisentan, macitentan, and ambrisentan), beta-blockers (e.g., bisoprolol and carvedilol), stem cells (allogeneic human cardiosphere-derived stem cells), and others. Some of these clinical trials report improvements in RVEF at different percentages: $3.9 \%$ after three months of trimetazidine treatment (NCT03273387), 10.4\% after six months of carvedilol (NCT00964678) oral treatment, $10.14 \%$ after six months of macitentan (NCT02310672) oral treatment, $7.65 \%$ and $5.8 \%$ after six months of ranolazine (NCT02829034, NCT01839110) oral treatments, and 7.54\% after six months of treprostinil inhalations combined with oral tadalafil treatment (NCT01305252). Besides, some clinical trials describe changes in TAPSE such as $7 \%$ from baseline after three months of anastrozole treatment (NCT01545336), a decrease from 1.88 to $1.79 \mathrm{~cm}$ after four months of QCC374 therapy (NCT02927366), and a decrease from 2.2 to $1.65 \mathrm{~cm}$ after nine months of tadalafil and ambrisentan combinational treatment (NCT01042158). These changes reported in RVEF and TAPSE suggest an improvement of the RV function.

Changes in RV volume parameters were also observed in different clinical trials. Treatment with macitentan caused changes in RVSV of $15.17 \mathrm{~mL}$, RVEDV of $-6.22 \mathrm{~mL}$, and RVESV of $16.39 \mathrm{~mL}$ (NCT02310672); besides, treatment with carvedilol caused a difference of $22.6 \mathrm{~mL}$ in RVESV (NCT00964678); these results were observed after six months of treatment with each compound. Along with these changes, improvements in RV mass were reported. Treatment with macitentan for six months caused a reduction of $10.10 \mathrm{~g}$ in RV mass (NCT02310672). Similarly, the combinatorial treatment with tadalafil and ambrisentan caused a change in RV mass from 32.5 to $28 \mathrm{~g}$ after nine months of treatment (NCT01042158), indicating an improvement in right ventricular remodeling.

As mentioned, most of the conducted clinical trials focus on enhancing cardiac function as a consequence of an improvement in pulmonary artery condition. The clinical trials mentioned here reported improvement in cardiac function with RV function parameters. Unfortunately, these clinical trials aimed at measuring RV function are not primarily 


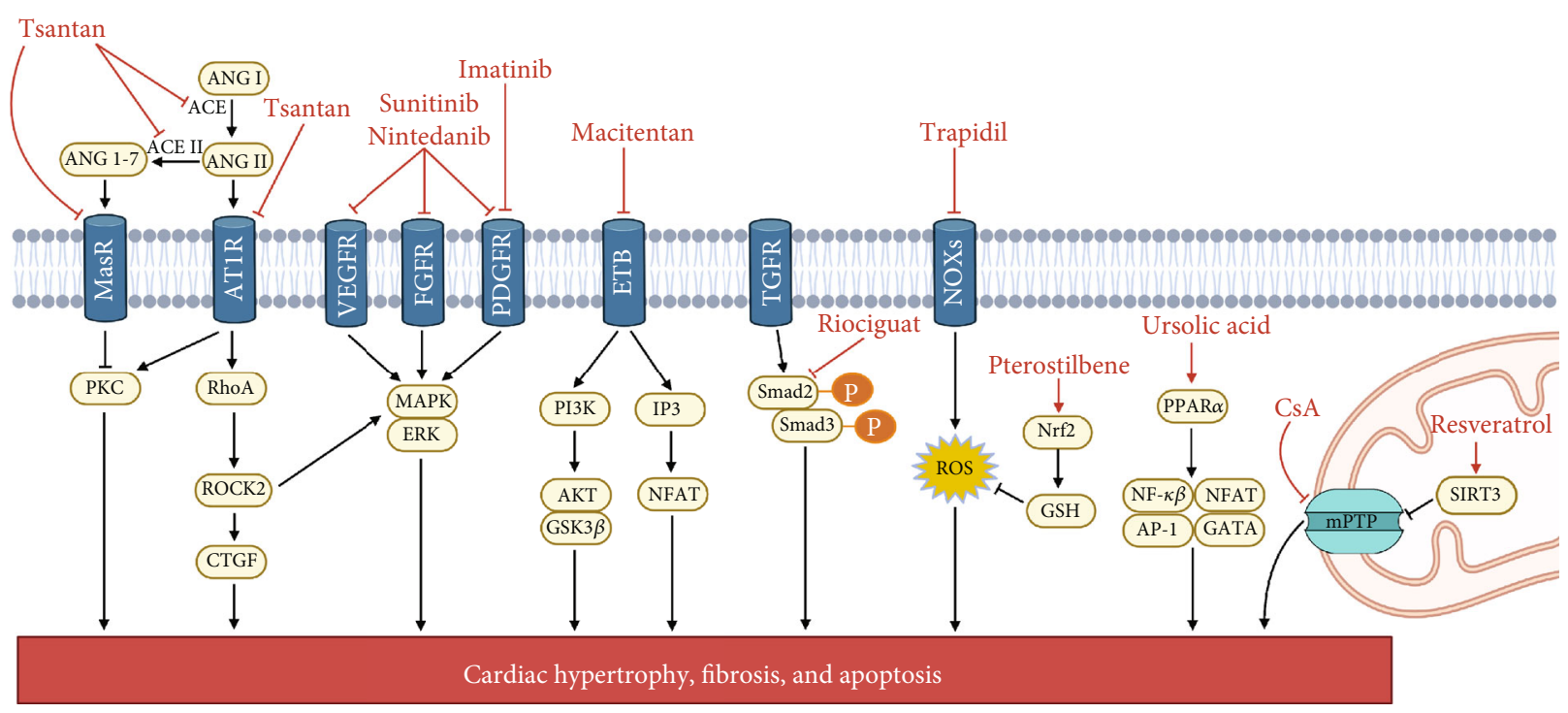

FIGURE 2: Mechanisms of cardioprotection in in vivo therapeutic approaches. Molecules and their effects are shown in red. Lines with arrows indicate activation/stimulation; lines with blunt ends indicate inhibition. Mechanism involved (1) surface receptors blockade: tsantan, sunitinib, nintedanib, imatinib, macitentan, and riociguat; (2) reactive oxygen species inhibition: trapidil and pterostilbene; (3) metabolic capacity preservation: ursolic acid, cyclosporin A (CsA), and resveratrol. ANG: angiotensin; ACE: angiotensin-converting enzyme; MasR: Mas receptor; AT1R: angiotensin II type 1 receptor; VEGFR: vascular endothelial growth factor receptor; FGFR: epidermal growth factor receptor; PDGFR: platelet-derived growth factor receptors; ETB: endothelin receptor type B; TGFR: transforming growth factor receptor; NOXs: nicotinamide adenine dinucleotide phosphate-oxidases; PKC: protein kinase C; ROCK: rho-associated protein kinase; CTGF: connective tissue growth factor; MAPK: mitogen-activated protein kinases; ERK: extracellular signal-regulated kinase; PI3K: phosphatidylinositol 3-kinase; AKT: protein kinase B; GSK3 $\beta$ : glycogen synthase kinase 3 beta; IP3: inositol trisphosphate; NFAT: nuclear factor of activated T cells; ROS: reactive oxygen species; Nrf2: nuclear factor E2-related factor 2; GSH: glutathione; PPAR $\alpha$ : peroxisome proliferator-activated receptor alpha; NF- $\kappa \beta$ : nuclear factor kappa-light-chain-enhancer of activated B cells; AP-1: activator protein 1; MPTP: mitochondrial permeability and transition pore; SIRT3: sirtuin 3. The figure was created with BioRender.com.

focused on molecular parameters, such as mRNA or protein markers of RV damage, which could be helpful in achieving a better understanding of PAH improvement in humans.

\subsection{Biomarkers in Right Ventricular Dysfunction. Although} the clinical trials described above focus on evaluating improvement in the functional parameters of the RV after administering treatment, some studies have evaluated molecular parameters that could be taken into account when evaluating the results of these treatments. Although most of these molecular parameters are not exclusive to right ventricular dysfunction, they could be used as a complementary tool in functional evaluations to determine the diagnosis and prognosis of RV dysfunction. For example, myocardial fibrosis is a hallmark of ventricular remodeling and can be detected by assessing myocardial interstitial collagen content. Although endocardial tissue biopsy is the gold standard in the diagnosis of myocardial fibrosis, researchers have proposed assessing a number of circulating biomarkers with serum analysis markers of collage type I and III turnover, such as procollagen type III amino-terminal propeptide (PIIINP), collagen type I carboxy-terminal telopeptide (CITP), and procollagen type I N-terminal propeptide (PINP), which might serve as surrogate estimates in approximating the intensity of fibrosis in the myocardium. PIIINP may also be a good indicator for right ventricular (SRV) remodeling [136, 137]. Furthermore, cartilage intermediate layer protein 1 (CILP1), an extracellular matrix (ECM) pro- tein involved in profibrotic signaling in the myocardium [138], was recently described as a novel biomarker of RV and LV pathological remodeling in patients with pulmonary hypertension. In one study, maladaptive RV patients had higher CILP1 concentrations than controls and those with LV hypertrophy and dilated cardiac myopathy in [139]. Previously, expression at the RNA level in heart mouse models was shown to be more pronounced in RV pressure overload than in LV pressure overload [140]. Another novel biomarker has been reported; fetal tenascin- $\mathrm{C}(\mathrm{Tn}-\mathrm{C})$ variants $(\mathrm{B}+$ and $\mathrm{C}+)$ are significantly elevated in patients with pulmonary hypertension and can be used to estimate both pulmonary vascular remodeling and RV load in patients with pulmonary hypertension [141]. Furthermore, in an animal model with monocrotaline-induced PAH, Tn-C overexpression has been demonstrated in cardiac tissue $[142,143]$. Moreover, it has been reported that elevated serum Interlukin-6 (IL-6) levels in pulmonary hypertension patients are associated with RV dysfunction, regardless of the burden of pulmonary vascular disease. The association between serum IL-6 levels and RV dysfunction may explain the increased mortality in pulmonary hypertension patients with elevated serum IL6 levels, but it is important to clarify that IL6 levels are also related to functional impairment in patients with left ventricular systolic heart failure[144]. $\mathrm{BNP}$ and N-terminal pro-BNP are the most commonly used biomarkers in PAH. Both hormones are measurable in plasma and serve as biomarkers of RV dysfunction [145]. 
TABLE 3: Clinical trials with aim in measuring RV function.

\begin{tabular}{|c|c|c|c|c|}
\hline $\begin{array}{l}\text { Clinicaltrials.gov } \\
\text { identifier }\end{array}$ & Trial status & Intervention & RV outcome measures & Results \\
\hline NCT03273387 & Completed & Trimetazidine & $\begin{array}{c}\text { Changes in RV ejection fraction } \\
\text { after } 3 \text { months }\end{array}$ & $\begin{array}{l}\text { Improvement of RVEF } \\
(3.9 \%) \text { from baseline }\end{array}$ \\
\hline NCT03835676 & Recruiting & Treprostinil & $\begin{array}{l}\text { Effects on right ventricular } \\
\text { structure and function using } \\
\text { echocardiography } \\
\text { Effects on right ventricular } \\
\text { structure and function using } \\
\text { cardiac magnetic resonance } \\
\text { imaging }\end{array}$ & No results reported \\
\hline NCT02253394 & $\begin{array}{l}\text { Terminated (low } \\
\text { enrollment) }\end{array}$ & $\begin{array}{l}\text { Ambrisentan plus } \\
\text { spironolactone }\end{array}$ & Effect on cardiac output & No results reported \\
\hline NCT04435782 & Not yet recruiting & JNJ-67896049 & $\begin{array}{c}\text { Change from baseline to week } 26 \\
\text { in RVSV, RVEDV, RVESV, RVEF, } \\
\text { mass, and RVGLS in participants } \\
\text { will be assessed by pulmonary } \\
\text { artery flow MRI }\end{array}$ & No results reported \\
\hline NCT02074449 & Completed & Treprostinil & $\begin{array}{c}\text { Change in RV coupling index } \\
\text { between baseline, titration at } 48-72 \\
\text { hours, and } 3 \text { months }\end{array}$ & No results reported \\
\hline NCT01545336 & Completed & Anastrozole & $\begin{array}{l}\text { Tricuspid annular plane systolic } \\
\text { excursion (TAPSE) from baseline } \\
\text { to } 3 \text { months }\end{array}$ & $7 \%$ change from baseline \\
\hline NCT02310672 & Completed & Macitentan & $\begin{array}{c}\text { Change from baseline in RVSV, } \\
\text { RVEDV, RVESV, RVEF, and mass } \\
\text { to week } 26\end{array}$ & $\begin{array}{l}\text { Change of } 15.17 \mathrm{~mL} \text { of } \\
\text { RVSV, }-6.22 \mathrm{~mL} \text { of RVEDV, } \\
-16.39 \mathrm{~mL} \text { of RVESV, } 10.14 \% \\
\text { of RVEF, and }-10.10 \mathrm{~g} \text { to } \\
\text { week } 26\end{array}$ \\
\hline NCT02169752 & $\begin{array}{c}\text { Terminated (PI left } \\
\text { National Jewish Health) }\end{array}$ & Ambrisentan & $\begin{array}{c}\text { Improvement in RV myocardial } \\
\text { strain from baseline to } 1,3 \text {, and } 6 \\
\text { months }\end{array}$ & No results reported \\
\hline NCT03236818 & Unknown & $\begin{array}{l}\text { ERA and PDE-5I } \\
\text { (sildenafil, tadalafil, } \\
\text { bosentan, macitentan) }\end{array}$ & Change in RVEF & No results reported \\
\hline NCT01083524 & Completed & Dichloroacetate sodium & Changes in RV size/function & No results reported \\
\hline NCT01246037 & Unknown & Bisoprolol & $\begin{array}{l}\text { Improvement of maladaptive } \\
\text { remodeling of the RV wall and } \\
\text { diastolic properties of RV }\end{array}$ & No results reported \\
\hline NCT00742014 & $\begin{array}{l}\text { Suspended (absorption of } \\
\text { oral sildenafil not } \\
\text { consistent) }\end{array}$ & Sildenafil & $\begin{array}{l}\text { Increase in end-systolic elastance } \\
\text { of the right ventricle from baseline }\end{array}$ & No results reported \\
\hline NCT01148836 & Completed & $\begin{array}{l}\text { Coenzyme Q-10 } \\
\text { Dietary supplement }\end{array}$ & $\begin{array}{l}\mathrm{RV} \text { outflow and myocardial } \\
\text { performance from baseline to } 3 \\
\text { months }\end{array}$ & $\begin{array}{l}\mathrm{RV} \text { outflow from } 11.3 \text { to } \\
13.5 \mathrm{~cm} \text { and performance } \\
\text { ratio from } 0.9 \text { to } 0.7\end{array}$ \\
\hline NCT01757808 & Completed & Ranolazine & Change in RV echo parameters & No results reported \\
\hline NCT03617458 & Recruiting & Metformin & $\begin{array}{l}\text { Change from baseline to week } 12 \\
\text { in RV myocardial muscle } \\
\text { triglyceride content, TAPSE, } \\
\text { RVEF, RV fractional area, RV } \\
\text { diastolic function, and RV free wall } \\
\text { longitudinal strain }\end{array}$ & No results reported \\
\hline NCT04062565 & Recruiting & Treprostinil & Change in RV diastolic stiffness & No results reported \\
\hline NCT02829034 & Completed & Ranolazine & $\begin{array}{l}\text { Change from baseline in RVEF to } \\
26 \text { weeks }\end{array}$ & $\begin{array}{l}\text { Change of } 7.56 \% \text { from } \\
\text { baseline }\end{array}$ \\
\hline NCT01839110 & Completed & Ranolazine & $\begin{array}{l}\text { Changes from baseline in RVEF to } \\
6 \text { months }\end{array}$ & $\begin{array}{c}\text { Change of } 5.8 \% \text { from } \\
\text { baseline }\end{array}$ \\
\hline
\end{tabular}


TABLE 3: Continued.

\begin{tabular}{|c|c|c|c|c|}
\hline $\begin{array}{l}\text { Clinicaltrials.gov } \\
\text { identifier }\end{array}$ & Trial status & Intervention & RV outcome measures & Results \\
\hline NCT02939599 & $\begin{array}{l}\text { Terminated (study was } \\
\text { terminated early for } \\
\text { strategic reasons; only } \\
\text { part I of the study was } \\
\text { completed) }\end{array}$ & QCC374 & $\begin{array}{c}\text { Change from baseline in RV Tei } \\
\text { index and RV fractional area at } \\
\text { week } 16\end{array}$ & $\begin{array}{l}\text { Tei index change of } 0.84 \text { and } \\
\text { fractional area of } 23.91 \%\end{array}$ \\
\hline NCT02927366 & $\begin{array}{l}\text { Terminated (study was } \\
\text { terminated early for } \\
\text { strategic reasons; only } \\
\text { part I of the study was } \\
\text { completed) }\end{array}$ & QCC374 & $\begin{array}{c}\text { Change from baseline in RV } \\
\text { fractional area, Tei index, and } \\
\text { TAPSE }\end{array}$ & $\begin{array}{c}\text { Change from } 20.17 \text { to } \\
20.70 \% \text { of fractional area, } \\
0.92 \text { to } 0.89 \text { of Tei index, and } \\
\text { TAPSE from } 1.88 \text { to } 1.79 \mathrm{~cm}\end{array}$ \\
\hline NCT00964678 & Completed & Carvedilol & $\begin{array}{c}\text { Change from baseline in RVEF and } \\
\text { RVESV to } 6 \text { months }\end{array}$ & $\begin{array}{l}\text { Change in RVEF of } 10.4 \% \\
\text { and RVESV of } 22.6 \mathrm{~mL}\end{array}$ \\
\hline NCT03344159 & $\begin{array}{l}\text { Suspended (COVID-19 } \\
\text { pandemic) }\end{array}$ & Spironolactone & $\begin{array}{c}\text { Change from baseline of RV wall } \\
\text { stress, structure, function, and area } \\
\text { of fibrosis }\end{array}$ & No results reported \\
\hline NCT02507011 & Terminated & Carvedilol & Mean change in RVEF & Change in RVEF of $10 \%$ \\
\hline NCT01174173 & Completed & Ranolazine & $\begin{array}{l}\text { Change from baseline in absolute } \\
\text { RV longitudinal strain to } 3 \text { months }\end{array}$ & $\begin{array}{l}\text { Change in RV longitudinal } \\
\text { strain from }-1.4 \text { to } 1.0 \%\end{array}$ \\
\hline NCT02744339 & Completed & Riociguat & $\begin{array}{c}\text { Change from baseline in RVEF and } \\
\text { RV volume to } 26 \text { weeks }\end{array}$ & No results reported \\
\hline NCT02102672 & Unknown & Trimetazidine & $\begin{array}{l}\text { Change from baseline in RV } \\
\text { function to } 3 \text { months }\end{array}$ & No results reported \\
\hline NCT03648385 & Recruiting & Dehydroepiandrosterone & $\begin{array}{c}\text { Chance from baseline in RV } \\
\text { longitudinal strain and RVEF to } 40 \\
\text { weeks }\end{array}$ & No results reported \\
\hline NCT01042158 & Completed & $\begin{array}{l}\text { Tadalafil and } \\
\text { ambrisentan }\end{array}$ & $\begin{array}{l}\text { Change from baseline in RV mass } \\
\text { and TAPSE to } 36 \text { weeks }\end{array}$ & $\begin{array}{c}\text { Change in RV mass from } \\
32.5 \text { to } 28 \mathrm{~g} \text { and TAPSE from } \\
2.2 \text { to } 1.65 \mathrm{~cm}\end{array}$ \\
\hline NCT03145298 & Recruiting & $\begin{array}{l}\text { Allogeneic human } \\
\text { cardiosphere-derived } \\
\text { stem cells }\end{array}$ & Change in RV ventricular function & No results reported \\
\hline NCT03362047 & Recruiting & $\begin{array}{l}\text { Riociguat and } \\
\text { macitentan }\end{array}$ & $\begin{array}{l}\text { Change from baseline in RV } \\
\text { function and contractility to } 12 \\
\text { weeks }\end{array}$ & No results reported \\
\hline NCT03449524 & Terminated & CXA-10 & $\begin{array}{c}\text { Change from baseline in RVEF to } 6 \\
\text { months }\end{array}$ & No results reported \\
\hline NCT01305252 & Completed & $\begin{array}{l}\text { Treprostinil inhalations } \\
\text { and tadalafil }\end{array}$ & $\begin{array}{l}\text { Change from baseline in RVEF to } \\
24 \text { weeks }\end{array}$ & Change of $7.45 \%$ in RVEF \\
\hline NCT01917136 & Completed & $\begin{array}{c}\text { 11C-acetate and } \\
{[18 \text { F }] \text { fluoro-2-deoxy-2- }} \\
\text { D-glucose }\end{array}$ & $\begin{array}{l}\text { Change from baseline in RVEF to } 6 \\
\text { months }\end{array}$ & Change of $7.56 \%$ of RVEF \\
\hline NCT00772135 & Unknown & Sildenafil citrate & $\begin{array}{c}\text { Change from baseline in RV } \\
\text { pressure }\end{array}$ & No results reported \\
\hline
\end{tabular}

However, they are not specific to RV damage and can be elevated in almost all heart diseases [146].

Additionally, cardiac troponin T (cTnT) is used less frequently but has been identified as an independent marker of mortality in patients with PAH [147]; cTnT levels must be correlated with functional and hemodynamic measures [148]. Currently, miRNAs are also important candidate biomarkers. Notwithstanding, most of the upregulated miRNAs in RV failure are similar to those in LV afterload stress. In a murine model of right ventricular hypertrophy (RVH) and right ventricular failure (RVF) using pulmonary artery con- striction, RV-specific miRNAs 34a, 28, 93, and 148a were found; however, none of these are increased in LV hypertrophy and failure induced by transverse aortic constriction [149]. Interestingly, a transcriptomic study of human RVH via RNA expression and network analysis using exclusively freshly isolated myocardium of pediatric patients with tetralogy of Fallot/pulmonary stenosis found that miR-371a and miR-372 are differentially expressed when compared to controls. The authors suggest that these miRNAs are potential biomarkers for diseases associated with RV pressure overload [150]. In a study with 40 patients with RV pressure overload 
TABLe 4: Possible therapeutic strategies to address key alterations in RV versus LV dysfunction.

\begin{tabular}{|c|c|c|}
\hline & Possible therapeutic strategies & Ref. \\
\hline Fibrosis & $\begin{array}{l}\text { Current antifibrotic therapies effective in LV do not reverse RV fibrosis, } \\
\text { possibly due to differences in ECM composition. }\end{array}$ & {$[69,70,156-159]$} \\
\hline Myocyte contraction & $\begin{array}{l}\text { There is improvement of sarcomere function by PKA activators since RV } \\
\text { myofilaments have lower } \mathrm{Ca}^{2+} \text { sensitivity. }\end{array}$ & {$[46-48,160,161]$} \\
\hline Inflammation & $\begin{array}{l}\text { RV has more macrophages and dendritic cells, which could mean } \\
\text { inflammation plays a more important role. }\end{array}$ & {$[162,163]$} \\
\hline Mitochondrial dynamics & $\begin{array}{l}\text { PAH presents excessive RV mitochondrial fission, which could indicate } \\
\text { significant mitochondrial quality control impairment. }\end{array}$ & {$[164-166]$} \\
\hline Mitochondrial function & $\begin{array}{l}\mathrm{RV} \text { has less mitochondrial content and a lower rate of oxidation; thus, } \\
\text { the preservation of mitochondrial integrity and membrane potential } \\
\text { improves RV function. }\end{array}$ & {$[43,53,121,167]$} \\
\hline
\end{tabular}

by pulmonary hypertension, it was reported that circulating levels of miR-21, miR-130a, miR-133b, miR-191, miR-204, and miR-208b were higher, while the levels of miR-1, miR26a, miR-29c, miR-34b, miR-451, and miR-1246 were lower in comparison to matched controls. This study also confirmed that a correlation exists between the severity of $\mathrm{PAH}$ and circulating levels of miR-133b and miR-208b with [151]. It was also shown that long noncoding RNA H19 is upregulated in decompensated RV from PAH patients and correlates with RV hypertrophy and fibrosis. These findings were corroborated in a rat model of monocrotaline and pulmonary artery banding. The authors propose that $\mathrm{H} 19$ is a promising biomarker for the prognosis and severity of RV dysfunction by PAH [152].

Additional research is needed to identify new biomarkers that can further improve diagnostic accuracy. It is important to define standard operating procedures for blood and tissue collection, processing, and storage, as well as miRNA analysis, to ensure precise quantification. Additionally, it is necessary to correlate all emerging biomarkers with right ventricular function for robust validation.

\section{Final Thoughts}

The ventricles have commonly been studied as individual entities; however, each ventricle must adapt its function to perform its respective role in coordination with each other. Structural differences between ventricles determine their physiological differences in function at the organ level. LV contraction involves radially constricting and longitudinally shortening the septum, while RV contraction is more passive since the RV's free wall lies flat against the septum when LV contracts. The prolonged AP in the LV and the slower contraction velocity in the RV may be a mechanism to coordinate whole-organ contraction. Changes in ECC may compensate for the differences in muscle thickness and ejection pressure to allow ventricles to synchronize at the end of the systole. Furthermore, the discrepancies reported in changes at different stages of the ECC may be due to the heterogeneity within and between ventricles $[26,31,153]$. Physiological differences in the structure, function, and molecular adaptations of the LV and RV result in different responses to stressful stimuli. While LV thickness helps to support higher pressures, a thin RV wall is highly susceptible to increases in vascular resistance. A better understanding of the differences in cellular and molecular alterations in the LV and RV due to remodeling and failure may facilitate the development of more effective therapeutic approaches. This understanding is especially important for the RV, given that the mechanisms related to its dysfunction are not as widely studied as those related to LV's dysfunction.

Advances in RV dysfunction diagnostics and therapeutics are needed to improve the early detection of the disease and improve prognosis. The determination and validation of new, less-invasive, and more accurate biomarkers is an important research area that has been strengthened by the description of ventricle differences in dysfunction. Additionally, the search for new therapeutic approaches that target RV has been fueled by the variation in response between the two ventricles. Some diverse therapeutic strategies could be beneficial in improving current treatments (Table 4), but they require further investigation to estimate their contribution to patient morbidity and mortality.

\section{Data Availability}

The data used to support the findings of this study are available from the corresponding authors upon request.

\section{Conflicts of Interest}

No conflicts of interest, financial or otherwise, are declared by the authors.

\section{Authors' Contributions}

Judith Bernal-Ramirez and Magda C. Díaz-Vesga contribute equally to this work.

\section{Acknowledgments}

The authors wish to acknowledge the financial support of Tecnológico de Monterrey, a CONACYT doctoral fellowship (Grant 492122 to J.B.R.). This work was supported by grants from the CONACYT (256577 to G.G.R. and 258197 to C.J.S.), Fronteras de la Ciencia Grant (0682 to G.G.R.), and Ciencia Básica (A1-S-43883 to G.G.R.); Agencia Nacional de Investigación y Desarrollo (ANID) grants Fondo Nacional 
de Desarrollo Científico y Tecnológico, FONDECYT, Chile (1180613 to Z.P. and 1211270 to C.Q. and Z.P.) and ANID fellowship (21191341 to M.C.D.); Fondo de Financiamiento de Centros de Investigación en Âreas Prioritarias, FONDAP, ACCDiS, Chile (15130011 to C.Q., and Z.P.); U-Redes Generación, Vicerrectoría de Investigación y Desarrollo, Universidad de Chile, Chile, (URG-035/1 to M.H., and Z.P.); and Puente-ICBM 2019 (to M.H.).

\section{References}

[1] D. Santos-Ribeiro, P. Mendes-Ferreira, C. Maia-Rocha, R. Adão, A. F. Leite-Moreira, and C. Brás-Silva, "Hypertension arterielle pulmonaire : connaissances de base pour les cliniciens," Archives of Cardiovascular Diseases, vol. 109, no. 10, pp. 550-561, 2016.

[2] F. S. de Man, M. L. Handoko, and A. Vonk-Noordegraaf, "The unknown pathophysiological relevance of right ventricular hypertrophy in pulmonary arterial hypertension," European Respiratory Journal, vol. 53, article 1900255, no. 4, 2019.

[3] N. Galiè, R. N. Channick, R. P. Frantz et al., "Risk stratification and medical therapy of pulmonary arterial hypertension," European Respiratory Journal, vol. 53, no. 1, article 1801889, 2019.

[4] A. Hemnes, A. M. K. Rothman, A. J. Swift, and L. S. Zisman, "role of biomarkers in evaluation, treatment and clinical studies of pulmonary arterial hypertension," Pulmonary Circulation, vol. 10, no. 4, 2020.

[5] R. L. Benza, D. P. Miller, M. Gomberg-Maitland et al., "Predicting survival in pulmonary arterial hypertension: insights from the Registry to Evaluate Early and Long-Term Pulmonary Arterial Hypertension Disease Management (REVEAL)," Circulation, vol. 122, no. 2, pp. 164-172, 2010.

[6] J. A. Mazurek, A. Vaidya, S. C. Mathai, J. D. Roberts, and P. R. Forfia, "Follow-up tricuspid annular plane systolic excursion predicts survival in pulmonary arterial hypertension," Pulmonary circulation, vol. 7, no. 2, pp. 361-371, 2017.

[7] A. Huertas, L. Tu, M. Humbert, and C. Guignabert, "Chronic inflammation within the vascular wall in pulmonary arterial hypertension: more than a spectator," Cardiovascular Research, vol. 116, no. 5, pp. 885-893, 2020.

[8] C. W. Yancy, M. Jessup, B. Bozkurt et al., "2016 ACC/AHA/HFSA Focused Update on New Pharmacological Therapy for Heart Failure: An Update of the 2013 ACCF/AHA Guideline for the Management of Heart Failure: A Report of the American College of Cardiology/American Heart Association Task Force on Clinical Practice Guidelines and the Heart Failure Society of America," Journal of cardiac failure, vol. 22, no. 9, pp. 659-669, 2016.

[9] M. A. Simon, "Assessment and treatment of right ventricular failure," Nature Reviews. Cardiology, vol. 10, no. 4, pp. 204218, 2013.

[10] F. Haddad, S. A. Hunt, D. N. Rosenthal, and D. J. Murphy, "Right ventricular function in cardiovascular disease, part I: anatomy, physiology, aging, and functional assessment of the right ventricle," Circulation, vol. 117, no. 11, pp. 14361448, 2008.

[11] D. J. Penny and A. N. Redington, "Function of the left and right ventricles and the interactions between them," Pediatric Critical Care Medicine, vol. 17, 8 Supplement 1, pp. S112S118, 2016.
[12] J. Sanz, D. Sánchez-Quintana, E. Bossone, H. J. Bogaard, and R. Naeije, "Anatomy, Function, and Dysfunction of the Right Ventricle:," Journal of the American College of Cardiology, vol. 73, no. 12, pp. 1463-1482, 2019.

[13] P. Delgado-Olguin, "Embryological origins: how does the right ventricle form," in Right Ventricular Physiology, Adaptation and Failure in Congenital and Acquired Heart Disease, pp. 1-17, Springer, 2018.

[14] F. Radu-Ioniță, E. Bontaş, V. Goleanu et al., "Heart embryology: overview," in Right Heart Pathology, pp. 3-24, Springer, 2018.

[15] G. Buckberg and J. I. E. Hoffman, "Right ventricular architecture responsible for mechanical performance: unifying role of ventricular septum," The Journal of Thoracic and Cardiovascular Surgery, vol. 148, no. 6, pp. 3166-3171.e4, 2014.

[16] D. H. MacIver, "The relative impact of circumferential and longitudinal shortening on left ventricular ejection fraction and stroke volume," Experimental and Clinical Cardiology, vol. 17, no. 1, pp. 5-11, 2012.

[17] D. Oken and R. Boucek, "Quantitation of collagen in human myocardium," Circulation Research, vol. 5, no. 4, pp. 357361, 1957.

[18] D. Sidebotham, "Pulmonary Hypertension," in Cardiothoracic Critical Care, D. Sidebotham, A. Mckee, M. Gillham, and L. JHBT-CCC, Eds., pp. 374-382, Elsevier, 2007.

[19] G. J. Crystal and P. S. Pagel, "Right ventricular perfusion: physiology and clinical implications," Anesthesiology, vol. 128, no. 1, pp. 202-218, 2018.

[20] K. M. Chin, N. H. S. Kim, and L. J. Rubin, "The right ventricle in pulmonary hypertension," Coronary Artery Disease, vol. 16, no. 1, pp. 13-18, 2005.

[21] J. C. Matthews and V. McLaughlin, “Acute right ventricular failure in the setting of acute pulmonary embolism or chronic pulmonary hypertension: a detailed review of the pathophysiology, diagnosis, and management," Current Cardiology Reviews, vol. 4, no. 1, pp. 49-59, 2008.

[22] F. Haddad, R. Doyle, D. J. Murphy, and S. A. Hunt, "Right ventricular function in cardiovascular disease, part II: pathophysiology, clinical importance, and management of right ventricular failure," Circulation, vol. 117, no. 13, pp. 17171731, 2008.

[23] J. M. Cordeiro, K. Calloe, R. Aschar-Sobbi et al., "Physiological roles of the transient outward current i I i sub to sub in normal and diseased hearts," Frontiers in Bioscience, vol. 8, no. 1, pp. 143-159, 2016.

[24] D. M. Bers, "Cardiac excitation-contraction coupling," Nature, vol. 415, no. 6868, pp. 198-205, 2002.

[25] E. Fernández-Sada, C. Silva-Platas, C. A. Villegas et al., "Cardiac responses to $\beta$-adrenoceptor stimulation is partly dependent on mitochondrial calcium uniporter activity," British Journal of Pharmacology, vol. 171, no. 18, pp. 42074221, 2014.

[26] K. Calloe, G. L. Aistrup, J. M. Di Diego, R. J. Goodrow, J. A. Treat, and J. M. Cordeiro, "Interventricular differences in sodium current and its potential role in Brugada syndrome," Physiological reports, vol. 6, no. 14, article e13787, 2018.

[27] J. J. Kim, J. Nemec, R. Papp, R. Strongin, J. J. Abramson, and G. Salama, "Bradycardia alters $\mathrm{Ca}(2+)$ dynamics enhancing dispersion of repolarization and arrhythmia risk," American Journal of Physiology. Heart and Circulatory Physiology, vol. 304, no. 6, pp. H848-H860, 2013. 
[28] J. M. Di Diego, Z. Q. Sun, and C. Antzelevitch, "I(to) and action potential notch are smaller in left vs. right canine ventricular epicardium," The American Journal of Physiology, vol. 271, no. 2, pp. H548-H561, 1996.

[29] R. P. Kondo, D. A. Dederko, C. Teutsch et al., "Comparison of contraction and calcium handling between right and left ventricular myocytes from adult mouse heart: a role for repolarization waveform," The Journal of Physiology, vol. 571, no. 1, pp. 131-146, 2006.

[30] O. Casis, M. Iriarte, M. Gallego, and J. A. Sanchez-Chapula, "Differences in regional distribution of $\mathrm{K}^{+}$current densities in rat ventricle," Life Sciences, vol. 63, no. 5, pp. 391-400, 1998.

[31] S. Brunet, F. Aimond, H. Li et al., "Heterogeneous expression of repolarizing, voltage-gated $\mathrm{K}+$ currents in adult mouse ventricles," The Journal of Physiology, vol. 559, no. 1, pp. 103-120, 2004.

[32] P. G. Volders, K. R. Sipido, E. Carmeliet, R. L. H. M. G. Spätjens, H. J. Wellens, and M. A. Vos, "Repolarizing K+ currents ITO1 and IKs are larger in right than left canine ventricular midmyocardium," Circulation, vol. 99, no. 2, pp. 206-210, 1999.

[33] Y. Tsuji, S. Zicha, X.-Y. Qi, I. Kodama, and S. Nattel, "Potassium channel subunit remodeling in rabbits exposed to longterm bradycardia or Tachycardia," Circulation, vol. 113, no. 3, pp. 345-355, 2006.

[34] T. Watanabe, L. M. Delbridge, J. O. Bustamante, and T. F. McDonald, "Heterogeneity of the action potential in isolated rat ventricular myocytes and tissue," Circulation Research, vol. 52, no. 3, pp. 280-290, 1983.

[35] A. Bueno-Orovio, B. M. Hanson, J. S. Gill, P. Taggart, and B. Rodriguez, "In vivo human left-to-right ventricular differences in rate adaptation transiently increase pro-arrhythmic risk following rate acceleration," PLoS One, vol. 7, no. 12, article e52234, 2012.

[36] J. Švíglerová, J. Kuncová, L. Nalos et al., "Cardiac remodeling in rats with renal failure shows interventricular differences," Experimental Biology and Medicine (Maywood, N.J.), vol. 237, no. 9, pp. 1056-1067, 2012.

[37] C. Ramanathan, P. Jia, R. Ghanem, K. Ryu, and Y. Rudy, "Activation and repolarization of the normal human heart under complete physiological conditions," Proceedings of the National Academy of Sciences of the United States of America, vol. 103, no. 16, pp. 6309-6314, 2006.

[38] S. V. Pandit, K. Kaur, S. Zlochiver et al., "Left-to-right ventricular differences in $\mathrm{I}_{\text {KATP }}$ underlie epicardial repolarization gradient during global ischemia," Heart rhythm, vol. 8, no. 11, pp. 1732-1739, 2011.

[39] V. Ramesh, M. J. Kresch, A. M. Katz, and D. H. Kim, "Characterization of $\mathrm{Ca}(2+)$-release channels in fetal and adult rat hearts," The American Journal of Physiology, vol. 269, no. 3, pp. H778-H782, 1995.

[40] K. M. Meurs, V. A. Lacombe, K. Dryburgh, P. R. Fox, P. R. Reiser, and M. D. Kittleson, "Differential expression of the cardiac ryanodine receptor in normal and arrhythmogenic right ventricular cardiomyopathy canine hearts," Human Genetics, vol. 120, no. 1, pp. 111-118, 2006.

[41] V. Sathish, A. Xu, M. Karmazyn, S. M. Sims, and N. Narayanan, "Mechanistic basis of differences in $\mathrm{Ca} 2+$ -handling properties of sarcoplasmic reticulum in right and left ventricles of normal rat myocardium," American Journal of Physiology. Heart and Circulatory Physiology, vol. 291, no. 1, pp. H88-H96, 2006.
[42] J. Sabourin, A. Boet, C. Rucker-Martin et al., " $\mathrm{Ca}^{2+}$ handling remodeling and STIM1L/Orai1/TRPC1/TRPC4 upregulation in monocrotaline-induced right ventricular hypertrophy," Journal of Molecular and Cellular Cardiology, vol. 118, pp. 208-224, 2018.

[43] E. Vázquez-Garza, J. Bernal-Ramírez, C. Jerjes-Sánchez et al., "Resveratrol prevents right ventricle remodeling and dysfunction in monocrotaline-induced pulmonary arterial hypertension with a limited improvement in the lung vasculature," Oxidative medicine and cellular longevity, vol. 2020, Article ID 1841527, 13 pages, 2020.

[44] J. Nagwekar, D. Duggal, R. Rich et al., "The spatial distribution of actin and mechanical cycle of myosin are different in right and left ventricles of healthy mouse hearts," Biochemistry, vol. 53, no. 48, pp. 7641-7649, 2014.

[45] J. Nagwekar, D. Duggal, R. Rich et al., "Differences in the spatial distribution of actin in the left and right ventricles of functioning rabbit hearts," Medical Photonics, vol. 27, pp. 1-8, 2018.

[46] J. Liang, K. Kazmierczak, A. I. Rojas, Y. Wang, and D. SzczesnaCordary, "The R21C mutation in cardiac troponin I imposes differences in contractile force generation between the left and right ventricles of knock-in mice," BioMed Research International, vol. 2015, Article ID 742536, 9 pages, 2015.

[47] C. L. Perreault, O. H. Bing, W. W. Brooks, B. J. Ransil, and J. P. Morgan, "Differential effects of cardiac hypertrophy and failure on right versus left ventricular calcium activation," Circulation Research, vol. 67, no. 3, pp. 707-712, 1990.

[48] R. J. Belin, M. P. Sumandea, G. A. Sievert et al., "Interventricular differences in myofilament function in experimental congestive heart failure," Pflügers Archiv, vol. 462, no. 6, pp. 795-809, 2011.

[49] W. Brooks, O. Bing, A. Blaustein, and P. Allen, "Comparison of contractile state and myosin isozymes of rat right and left ventricular myocardium," Journal of Molecular and Cellular Cardiology, vol. 19, no. 5, pp. 433-440, 1987.

[50] H. Krug, K. Punkt, and L. Bittorf, "The higher myosin ATPase activity in the right heart ventricle of the rat, proved by histophotometry," Acta Histochemica, vol. 82, no. 1, pp. 115-119, 1987.

[51] R. A. Bassani, J. W. Bassani, and D. M. Bers, "Relaxation in ferret ventricular myocytes: unusual interplay among calcium transport systems," The Journal of Physiology, vol. 476, no. 2, pp. 295-308, 1994.

[52] V. G. Sharov, A. Goussev, M. Lesch, S. Goldstein, and H. N. Sabbah, "Abnormal mitochondrial function in myocardium of dogs with chronic heart failure," Journal of Molecular and Cellular Cardiology, vol. 30, no. 9, pp. 1757-1762, 1998.

[53] R. Nogueira-Ferreira, R. Ferreira, A. I. Padrão et al., "One year of exercise training promotes distinct adaptations in right and left ventricle of female Sprague-Dawley rats," Journal of Physiology and Biochemistry, vol. 75, no. 4, pp. 561-572, 2019.

[54] S. Singh, F. C. White, and C. M. Bloor, "Myocardial morphometric characteristics in swine," Circulation Research, vol. 49, no. 2, pp. 434-441, 1981.

[55] I. Starr, W. A. Jeffers, and R. H. Meade Jr., "The absence of conspicuous increments of venous pressure after severe damage to the right ventricle of the dog, with a discussion of the relation between clinical congestive failure and heart disease," American Heart Journal, vol. 26, no. 3, pp. 291301, 1943 . 
[56] N. H. Guiha, C. J. Limas, and J. N. Cohn, "Predominant right ventricular dysfunction after right ventricular destruction in the dog," The American Journal of Cardiology, vol. 33, no. 2, pp. 254-258, 1974.

[57] J. M. Isner and W. C. Roberts, "Right ventricular infarction complicating left ventricular infarction secondary to coronary heart disease: Frequency, location, associated findings and significance from analysis of 236 necropsy patients with acute or healed myocardial infarction," The American Journal of Cardiology, vol. 42, no. 6, pp. 885-894, 1978.

[58] S. Turkoglu, M. Erden, and M. Ozdemir, "Un infarctus ventriculaire droit isole cause par une occlusion de la branche ventriculaire droite en l'absence d'intervention coronaire percutanee," The Canadian Journal of Cardiology, vol. 24, no. 10, pp. 793-794, 2008.

[59] T. Levin and J. A. Goldstein, "Right ventricular myocardial infarction - UpToDate," https://www.uptodate.com/ contents/right-ventricular-myocardial-infarction/.

[60] G. A. Heresi, W. H. W. Tang, M. Aytekin, J. Hammel, S. L. Hazen, and R. A. Dweik, "Sensitive cardiac troponin I predicts poor outcomes in pulmonary arterial hypertension," The European Respiratory Journal, vol. 39, no. 4, pp. 939-944, 2012.

[61] C. P. Anaruma, R. M. Pereira, K. Cristina da Cruz Rodrigues et al., "Rock protein as cardiac hypertrophy modulator in obesity and physical exercise," Life sciences, vol. 254, article 116955, 2020.

[62] F. Antigny, O. Mercier, M. Humbert, and J. Sabourin, “Alteration du couplage excitation-contraction et relaxation dans le remodelage ventriculaire droit due a une hypertension arterielle pulmonaire," Archives of Cardiovascular Diseases, vol. 113, no. 1, pp. 70-84, 2020.

[63] I. Friehs, D. B. Cowan, Y.-H. Choi et al., "Pressure-overload hypertrophy of the developing heart reveals activation of divergent gene and protein pathways in the left and right ventricular myocardium," American Journal of Physiology. Heart and Circulatory Physiology, vol. 304, no. 5, pp. H697-H708, 2013.

[64] R. Schreckenberg, M. Rebelo, A. Deten et al., "Specific mechanisms underlying right heart failure: the missing upregulation of superoxide dismutase-2 and its decisive role in antioxidative defense," Antioxidants \& Redox Signaling, vol. 23, no. 15, pp. 1220-1232, 2015.

[65] J. Heger, R. Schulz, and G. Euler, "Molecular switches under TGF $\beta$ signalling during progression from cardiac hypertrophy to heart failure," British Journal of Pharmacology, vol. 173, no. 1, pp. 3-14, 2016.

[66] S. Ikeda, K. Satoh, N. Kikuchi et al., "Crucial role of rhokinase in pressure overload-induced right ventricular hypertrophy and dysfunction in mice," Arteriosclerosis, Thrombosis, and Vascular Biology, vol. 34, no. 6, pp. 12601271, 2014.

[67] S. Minegishi, K. Kitahori, A. Murakami, and M. Ono, "Mechanism of pressure-overload right ventricular hypertrophy in infant rabbits," International Heart Journal, vol. 52, no. 1, pp. 56-60, 2011.

[68] M. Yildiz, A. A. Oktay, M. H. Stewart, R. V. Milani, H. O. Ventura, and C. J. Lavie, "Left ventricular hypertrophy and hypertension," Progress in Cardiovascular Diseases, vol. 63, no. 1, pp. 10-21, 2020.

[69] E. Herpel, S. Singer, C. Flechtenmacher et al., "Extracellular matrix proteins and matrix metalloproteinases differ between various right and left ventricular sites in end-stage cardiomyopathies," Virchows Archiv, vol. 446, no. 4, article 1177, pp. 369-378, 2005.

[70] S. Andersen, J. Birkmose Axelsen, S. Ringgaard et al., "Pressure overload induced right ventricular remodeling is not attenuated by the anti-fibrotic agent pirfenidone," Pulmonary circulation, vol. 9, no. 2, 2019.

[71] Y. C. Bryce, R. Perez-Johnston, E. B. Bryce, B. Homayoon, and E. G. Santos-Martin, "Pathophysiology of right ventricular failure in acute pulmonary embolism and chronic thromboembolic pulmonary hypertension: a pictorial essay for the interventional radiologist," Insights Into Imaging, vol. 10, no. 1, p. 18, 2019.

[72] W. Pang, Z. Zhang, Y. Zhang et al., "Extracellular matrix collagen biomarkers levels in patients with chronic thromboembolic pulmonary hypertension," Journal of Thrombosis and Thrombolysis, vol. 52, no. 1, pp. 48-58, 2021.

[73] B. Kojonazarov, T. Novoyatleva, M. Boehm et al., "p38 MAPK inhibition improves heart function in pressureloaded right ventricular hypertrophy," American Journal of Respiratory Cell and Molecular Biology, vol. 57, no. 5, pp. 603-614, 2017.

[74] S. A. Bageghni, K. E. Hemmings, N. Zava et al., "Cardiac fibroblast-specific p $38 \alpha$ MAP kinase promotes cardiac hypertrophy via a putative paracrine interleukin- 6 signaling mechanism," The FASEB Journal, vol. 32, no. 9, pp. 4941-4954, 2018.

[75] L. Lu, D. Wu, L. Li, and L. Chen, "Apelin/APJ system: a bifunctional target for cardiac hypertrophy," International Journal of Cardiology, vol. 230, pp. 164-170, 2017.

[76] D. Wu, F. Xie, L. Xiao et al., "Caveolin-1-autophagy pathway mediated cardiomyocyte hypertrophy induced by apelin-13," DNA and Cell Biology, vol. 36, no. 8, pp. 611-618, 2017.

[77] V. N. Parikh, J. Liu, C. Shang et al., "Apelin and APJ orchestrate complex tissue-specific control of cardiomyocyte hypertrophy and contractility in the hypertrophy-heart failure transition," American Journal of Physiology. Heart and Circulatory Physiology, vol. 315, no. 2, pp. H348-H356, 2018.

[78] I. Falcão-Pires, N. Gonçalves, T. Henriques-Coelho, D. Moreira-Gonçalves, R. J. Roncon-Albuquerque, and A. F. Leite-Moreira, "Apelin decreases myocardial injury and improves right ventricular function in monocrotalineinduced pulmonary hypertension," American Journal of Physiology. Heart and Circulatory Physiology, vol. 296, no. 6, pp. H2007-H2014, 2009.

[79] Y. Olgar, M. C. Celen, B. E. Yamasan, N. Ozturk, B. Turan, and S. Ozdemir, "Rho-kinase inhibition reverses impaired $\mathrm{Ca}^{2+}$ handling and associated left ventricular dysfunction in pressure overload-induced cardiac hypertrophy," Cell Calcium, vol. 67, pp. 81-90, 2017.

[80] B. R. Cowan and A. A. Young, "Left ventricular hypertrophy and renin-angiotensin system blockade," Current Hypertension Reports, vol. 11, no. 3, pp. 167-172, 2009.

[81] L. Zhou, B. Ma, and X. Han, "The role of autophagy in angiotensin II-induced pathological cardiac hypertrophy," Journal of Molecular Endocrinology, vol. 57, no. 4, pp. R143-R152, 2016.

[82] S. Gallo, A. Vitacolonna, A. Bonzano, P. Comoglio, and T. Crepaldi, "ERK: a key player in the pathophysiology of cardiac hypertrophy," International journal of molecular sciences, vol. 20, no. 9, p. 2164, 2019. 
[83] H. K. Park, S. J. Park, C. S. Kim, Y. W. Paek, J. U. Lee, and W. J. Lee, "Enhanced gene expression of renin-angiotensin system, TGF-beta1, endothelin-1 and nitric oxide synthase in right-ventricular hypertrophy," Pharmacological Research, vol. 43, no. 3, pp. 265-273, 2001.

[84] I.-P. Chou, Y.-P. Chiu, S.-T. Ding, B.-H. Liu, Y. Y. Lin, and C.-Y. Chen, "Adiponectin receptor 1 overexpression reduces lipid accumulation and hypertrophy in the heart of dietinduced obese mice-possible involvement of oxidative stress and autophagy," Endocrine Research, vol. 39, no. 4, pp. 173179, 2014.

[85] L. Weng, W. Zhang, Y. Ye et al., "Aliskiren ameliorates pressure overload-induced heart hypertrophy and fibrosis in mice," Acta Pharmacologica Sinica, vol. 35, no. 8, pp. 10051014,2014

[86] L. Long, X. Yang, M. Southwood et al., "Chloroquine prevents progression of experimental pulmonary hypertension via inhibition of autophagy and lysosomal bone morphogenetic protein type II receptor degradation," Circulation Research, vol. 112, no. 8, pp. 1159-1170, 2013.

[87] D. K. Rawat, A. Alzoubi, R. Gupte et al., "Increased reactive oxygen species, metabolic maladaptation, and autophagy contribute to pulmonary arterial hypertension-induced ventricular hypertrophy and diastolic heart failure," Hypertens (Dallas, Tex 1979), vol. 64, no. 6, pp. 1266-1274, 2014.

[88] F. Cacciapuoti, "Role of ubiquitin-proteasome system (UPS) in left ventricular hypertrophy (LVH)," American journal of cardiovascular disease, vol. 4, no. 1, pp. 1-5, 2014.

[89] T. Heitmeier, A. Sydykov, C. Lukas et al., "Altered proteasome function in right ventricular hypertrophy," Cardiovascular Research, vol. 116, no. 2, pp. 406-415, 2020.

[90] V. Rajagopalan, M. Zhao, S. Reddy et al., "Altered ubiquitinproteasome signaling in right ventricular hypertrophy and failure," American Journal of Physiology. Heart and Circulatory Physiology, vol. 305, no. 4, pp. H551-H562, 2013.

[91] R. Kerkela and T. Force, "Recent insights into cardiac hypertrophy and left ventricular remodeling," Current Heart Failure Reports, vol. 3, no. 1, pp. 14-18, 2006.

[92] B. S. Ferguson, B. C. Harrison, M. Y. Jeong et al., "Signaldependent repression of DUSP5 by class I HDACs controls nuclear ERK activity and cardiomyocyte hypertrophy," Proceedings of the National Academy of Sciences of the United States of America, vol. 110, no. 24, pp. 9806-9811, 2013.

[93] P. Chelladurai, O. Boucherat, K. Stenmark et al., "Targeting histone acetylation in pulmonary hypertension and right ventricular hypertrophy," British Journal of Pharmacology, vol. 178, no. 1, pp. 54-71, 2021.

[94] J. Y. Y. Ooi, N. K. Tuano, H. Rafehi et al., "HDAC inhibition attenuates cardiac hypertrophy by acetylation and deacetylation of target genes," Epigenetics, vol. 10, no. 5, pp. 418-430, 2015.

[95] H. J. Bogaard, S. Mizuno, A. A. Hussaini et al., "Suppression of histone deacetylases worsens right ventricular dysfunction after pulmonary artery banding in rats," American Journal of Respiratory and Critical Care Medicine, vol. 183, no. 10, pp. 1402-1410, 2011.

[96] Y. Seta, K. Shan, B. Bozkurt, H. Oral, and D. L. Mann, "Basic mechanisms in heart failure: the cytokine hypothesis," Journal of Cardiac Failure, vol. 2, no. 3, pp. 243-249, 1996.

[97] X.-Q. Sun, A. Abbate, and H.-J. Bogaard, "Role of cardiac inflammation in right ventricular failure," Cardiovascular Research, vol. 113, no. 12, pp. 1441-1452, 2017.
[98] E. S. Chung, M. Packer, K. H. Lo, A. A. Fasanmade, J. T. Willerson, and Anti-TNF Therapy Against Congestive Heart Failure Investigators, "Randomized, double-blind, placebocontrolled, pilot trial of infliximab, a chimeric monoclonal antibody to tumor necrosis factor- $\alpha$, in patients with moderate-to-severe heart failure," Circulation, vol. 107, no. 25, pp. 3133-3140, 2003.

[99] B. W. van Tassell, N. A. Abouzaki, C. Oddi Erdle et al., "Interleukin-1 blockade in acute decompensated heart failure: a randomized, double-blinded, placebo-controlled pilot study," Journal of Cardiovascular Pharmacology, vol. 67, no. 6, pp. 544-551, 2016.

[100] C. S. P. Lam, V. L. Roger, R. J. Rodeheffer, B. A. Borlaug, F. T. Enders, and M. M. Redfield, "Pulmonary hypertension in heart failure with preserved ejection fraction: a communitybased study," Journal of the American College of Cardiology, vol. 53, no. 13, pp. 1119-1126, 2009.

[101] M. Guazzi and R. Naeije, "Pulmonary hypertension in heart failure: pathophysiology, pathobiology, and emerging clinical perspectives," Journal of the American College of Cardiology, vol. 69, no. 13, pp. 1718-1734, 2017.

[102] A. Kemdem, F. Lemaitre, R. Lovat, V. Siraux, P. Dillien, and F. Dive, "Acute hypoxic pulmonary hypertension associated with right heart failure," Acta Cardiologica, vol. 75, no. 6, pp. 544-548, 2020.

[103] C. E. Ventetuolo and J. R. Klinger, "Management of acute right ventricular failure in the intensive care unit," Annals of the American Thoracic Society, vol. 11, no. 5, pp. 811$822,2014$.

[104] S. Ghio, C. Raineri, L. Scelsi, M. Ašanin, M. Polovina, and P. Seferovic, "Pulmonary hypertension and right ventricular remodeling in HFpEF and HFrEF," Heart Failure Reviews, vol. 25, no. 1, pp. 85-91, 2020.

[105] J. J. Ryan, J. Huston, S. Kutty et al., "Right ventricular adaptation and failure in pulmonary arterial hypertension," The Canadian Journal of Cardiology, vol. 31, no. 4, pp. 391-406, 2015.

[106] S. Rosenkranz, J. S. R. Gibbs, R. Wachter, T. de Marco, A. Vonk-Noordegraaf, and J.-L. Vachiéry, "Left ventricular heart failure and pulmonary hypertension," European Heart Journal, vol. 37, no. 12, pp. 942-954, 2016.

[107] K. Nochioka, G. Querejeta Roca, B. Claggett et al., "Right ventricular function, right ventricular-pulmonary artery coupling, and heart failure risk in 4 US communities: the atherosclerosis risk in communities (ARIC) study," JAMA Cardiology, vol. 3, no. 10, pp. 939-948, 2018.

[108] I. Iglesias-Garriz, C. Olalla-Gómez, C. Garrote et al., "Contribution of right ventricular dysfunction to heart failure mortality: a meta-analysis," Reviews in Cardiovascular Medicine, vol. 13, no. 2-3, pp. e62-e69, 2012.

[109] V. Melenovsky, S.-J. Hwang, G. Lin, M. M. Redfield, and B. A. Borlaug, "Right heart dysfunction in heart failure with preserved ejection fraction," European Heart Journal, vol. 35, no. 48 , pp. 3452-3462, 2014.

[110] F. Bursi, S. M. McNallan, M. M. Redfield et al., "Pulmonary pressures and death in heart failure: a community study," Journal of the American College of Cardiology, vol. 59, no. 3, pp. 222-231, 2012.

[111] M. A. Konstam, M. S. Kiernan, D. Bernstein et al., "Evaluation and management of right-sided heart failure: a scientific statement from the American Heart Association," Circulation, vol. 137, no. 20, pp. e578-e622, 2018. 
[112] S. E. Altin and P. C. Schulze, "Metabolism of the right ventricle and the response to hypertrophy and failure," Progress in Cardiovascular Diseases, vol. 55, no. 2, pp. 229233, 2012.

[113] N. Saadane, L. Alpert, and L. E. Chalifour, "Expression of immediate early genes, GATA-4, and Nkx-2.5 in adrenergicinduced cardiac hypertrophy and during regression in adult mice," British Journal of Pharmacology, vol. 127, no. 5, pp. 1165-1176, 1999.

[114] D. S. Lee and Y. W. Jung, "Protective effect of right ventricular mitochondrial damage by cyclosporine a in monocrotalineinduced pulmonary hypertension," Korean circulation journal, vol. 48, no. 12, pp. 1135-1144, 2018.

[115] J. J. Ryan and S. L. Archer, "The right ventricle in pulmonary arterial hypertension: disorders of metabolism, angiogenesis and adrenergic signaling in right ventricular failure," Circulation Research, vol. 115, no. 1, pp. 176-188, 2014.

[116] T. A. Karim, N. T. Boardman, and M. C. Sanchez, "Mitochondrial respiratory states and rates," 2019.

[117] L. Piao, Y.-H. Fang, K. Parikh, J. J. Ryan, P. T. Toth, and S. L. Archer, "Cardiac glutaminolysis: a maladaptive cancer metabolism pathway in the right ventricle in pulmonary hypertension," Journal of Molecular Medicine, vol. 91, no. 10, pp. 1185-1197, 2013.

[118] B. Chowdhury, A. Z. Luu, V. Z. Luu et al., “The SGLT2 inhibitor empagliflozin reduces mortality and prevents progression in experimental pulmonary hypertension," Biochemical and Biophysical Research Communications, vol. 524, no. 1, pp. 50-56, 2020.

[119] Y.-H. Fang, L. Piao, Z. Hong et al., "Therapeutic inhibition of fatty acid oxidation in right ventricular hypertrophy: exploiting Randle's cycle," Journal of Molecular Medicine, vol. 90, no. 1, pp. 31-43, 2012.

[120] E. Legchenko, P. Chouvarine, P. Borchert et al., "PPAR $\gamma$ agonist pioglitazone reverses pulmonary hypertension and prevents right heart failure via fatty acid oxidation," Science translational medicine, vol. 10, no. 438, p. eaao0303, 2018.

[121] J. Bernal-Ramírez, C. Silva-Platas, C. Jerjes-Sánchez et al., "Resveratrol Prevents Right Ventricle Dysfunction, Calcium Mishandling, and Energetic Failure via SIRT3 Stimulation in Pulmonary Arterial Hypertension," Oxidative Medicine and Cellular Longevity, vol. 2021, Article ID 9912434, 15 pages, 2021.

[122] Å. T. Røe, J. M. Aronsen, K. Skårdal et al., "Increased passive stiffness promotes diastolic dysfunction despite improved $\mathrm{Ca} 2+$ handling during left ventricular concentric hypertrophy," Cardiovascular Research, vol. 113, no. 10, pp. 1161-1172, 2017.

[123] A. M. Gómez, G. Ruiz-Hurtado, J.-P. Benitah, and A. Domínguez-Rodríguez, " $\mathrm{Ca}(2+)$ fluxes involvement in gene expression during cardiac hypertrophy," Current Vascular Pharmacology, vol. 11, no. 4, pp. 497-506, 2013.

[124] R. Paulin, G. Sutendra, V. Gurtu et al., “A miR-208-Mef2 axis drives the decompensation of right ventricular function in pulmonary hypertension," Circulation Research, vol. 116, no. 1, pp. 56-69, 2015.

[125] R. Adão, P. Mendes-Ferreira, C. Maia-Rocha et al., "Neuregulin-1 attenuates right ventricular diastolic stiffness in experimental pulmonary hypertension," Clinical and Experimental Pharmacology \& Physiology, vol. 46, no. 3, pp. 255-265, 2019.

[126] X. An, S. Li, X. Weng et al., "Maxingxiongting mixture attenuates hypoxia pulmonary arterial hypertension to improve right ventricular hypertrophy by inhibiting the rho-kinase signaling pathway," Journal of Traditional Chinese Medicine= Chung $i$ tsa Chih Ying wen pan, vol. 40, no. 6, pp. 992-998, 2020.

[127] Z. Dang, S. Su, G. Jin et al., "Tsantan Sumtang attenuated chronic hypoxia-induced right ventricular structure remodeling and fibrosis by equilibrating local ACE-AngII-AT1R/ACE2Ang1-7-Mas axis in rat," Journal of Ethnopharmacology, vol. 250, p. 112470, 2020.

[128] X. Gao, Z. Zhang, X. Li et al., "Ursolic acid improves monocrotaline-induced right ventricular remodeling by regulating metabolism," Journal of Cardiovascular Pharmacology, vol. 75, no. 6, pp. 545-555, 2020.

[129] N. Rol, M. A. de Raaf, X. Q. Sun et al., "Nintedanib improves cardiac fibrosis but leaves pulmonary vascular remodelling unaltered in experimental pulmonary hypertension," Cardiovascular Research, vol. 115, no. 2, pp. 432-439, 2019.

[130] Z. P. Leong, A. Okida, M. Higuchi, Y. Yamano, and Y. Hikasa, "Reversal effects of low-dose imatinib compared with sunitinib on monocrotaline-induced pulmonary and right ventricular remodeling in rats," Vascular Pharmacology, vol. 100, pp. 41-50, 2018.

[131] N. Rai, S. Veeroju, Y. Schymura et al., "Effect of riociguat and sildenafil on right heart remodeling and function in pressure overload induced model of pulmonary arterial banding," BioMed Research International, vol. 2018, Article ID 3293584, 9 pages, 2018.

[132] A. Mamazhakypov, A. Weiß, S. Zukunft et al., "Effects of macitentan and tadalafil monotherapy or their combination on the right ventricle and plasma metabolites in pulmonary hypertensive rats," Pulmonary circulation, vol. 10, no. 4, p. 204589402094728, 2020.

[133] E. G. Schmuck, T. A. Hacker, D. A. Schreier, N. C. Chesler, and Z. Wang, "Beneficial effects of mesenchymal stem cell delivery via a novel cardiac bioscaffold on right ventricles of pulmonary arterial hypertensive rats," American Journal of Physiology-Heart and Circulatory Physiology, vol. 316, no. 5, pp. H1005-H1013, 2019.

[134] D. Lacerda, P. Türck, C. Campos-Carraro et al., "Pterostilbene improves cardiac function in a rat model of right heart failure through modulation of calcium handling proteins and oxidative stress," Applied Physiology, Nutrition, and Metabolism, vol. 45, no. 9, pp. 987-995, 2020.

[135] P. Türck, D. S. Lacerda, C. C. Carraro et al., "Trapidil improves hemodynamic, echocardiographic and redox state parameters of right ventricle in monocrotaline-induced pulmonary arterial hypertension model," Biomedicine \& Pharmacotherapy, vol. 103, pp. 182-190, 2018.

[136] M. Lipczyńska, P. Szymański, M. Kumor, A. Klisiewicz, and P. Hoffman, "Collagen turnover biomarkers and systemic right ventricle remodeling in adults with previous atrial switch procedure for transposition of the great arteries," PLoS One, vol. 12, no. 8, article e0180629, 2017.

[137] B. López, A. González, and J. Díez, "Circulating biomarkers of collagen metabolism in cardiac diseases," Circulation, vol. 121, no. 14, pp. 1645-1654, 2010.

[138] F. A. van Nieuwenhoven, C. Munts, R. C. op't Veld et al., "Cartilage intermediate layer protein 1 (CILP1): a novel mediator of cardiac extracellular matrix remodelling," Scientific Reports, vol. 7, no. 1, article 16201, p. 16042, 2017.

[139] S. Keranov, O. Dörr, L. Jafari et al., "CILP1 as a biomarker for right ventricular maladaptation in pulmonary hypertension," European Respiratory Journal, vol. 57, no. 4, p. 1901192, 2021. 
[140] K. Kreymborg, S. Uchida, P. Gellert et al., "Identification of right heart-enriched genes in a murine model of chronic outflow tract obstruction," Journal of Molecular and Cellular Cardiology, vol. 49, no. 4, pp. 598-605, 2010.

[141] I. Rohm, K. Grün, L. M. Müller et al., "Increased serum levels of fetal tenascin-C variants in patients with pulmonary hypertension: novel biomarkers reflecting vascular remodeling and right ventricular dysfunction?," International journal of molecular sciences, vol. 18, no. 11, p. 2371, 2017.

[142] J. Correia-Pinto, T. Henriques-Coelho, R. J. RonconAlbuquerque et al., "Time course and mechanisms of left ventricular systolic and diastolic dysfunction in monocrotalineinduced pulmonary hypertension," Basic Research in Cardiology, vol. 104, no. 5, pp. 535-545, 2009.

[143] M. Hessel, P. Steendijk, B. den Adel, C. Schutte, and A. van der Laarse, "Pressure overload-induced right ventricular failure is associated with re-expression of myocardial tenascin-C and elevated plasma tenascin-C levels," Cellular Physiology and Biochemistry, vol. 24, no. 3-4, pp. 201-210, 2009.

[144] K. W. Prins, S. L. Archer, M. Pritzker et al., "Interleukin-6 is independently associated with right ventricular function in pulmonary arterial hypertension," The Journal of Heart and Lung Transplantation, vol. 37, no. 3, pp. 376-384, 2018.

[145] N. M. Pradhan, C. Mullin, and H. D. Poor, "Biomarkers and right ventricular dysfunction," Critical Care Clinics, vol. 36, no. 1, pp. 141-153, 2020.

[146] N. Galiè, M. Humbert, J.-L. Vachiery et al., "2015 ESC/ERS guidelines for the diagnosis and treatment of pulmonary Hypertension," European Heart Journal, vol. 37, no. 1, pp. 67-119, 2016.

[147] A. Torbicki, M. Kurzyna, P. Kuca et al., "Detectable serum cardiac troponin $\mathrm{T}$ as a marker of poor prognosis among patients with chronic precapillary pulmonary hypertension," Circulation, vol. 108, no. 7, pp. 844-848, 2003.

[148] M. Wilkins, "Pulmonary hypertension: proteins in the blood," Global Cardiology Science \& Practice, vol. 2020, no. 1, article e202007, 2020.

[149] S. Reddy, M. Zhao, D.-Q. Hu et al., "Dynamic microRNA expression during the transition from right ventricular hypertrophy to failure," Physiological Genomics, vol. 44, no. 10, pp. 562-575, 2012.

[150] P. Chouvarine, J. Photiadis, R. Cesnjevar et al., "RNA expression profiles and regulatory networks in human right ventricular hypertrophy due to high pressure load," iScience, vol. 24, no. 3, article 102232, 2021.

[151] C. Wei, H. Henderson, C. Spradley et al., "Circulating miRNAs as potential marker for pulmonary hypertension," PLoS One, vol. 8, no. 5, article e64396, 2013.

[152] J. Omura, K. Habbout, T. Shimauchi et al., "Identification of long noncoding RNA H19 as a new biomarker and therapeutic target in right ventricular failure in pulmonary arterial hypertension," Circulation, vol. 142, no. 15, pp. 14641484, 2020.

[153] B. C. Knollmann, A. N. Katchman, and M. R. Franz, "Monophasic action potential recordings from intact mouse heart: validation, regional heterogeneity, and relation to refractoriness," Journal of Cardiovascular Electrophysiology, vol. 12, no. 11, pp. 1286-1294, 2001.

[154] G. Münch, B. Bölck, A. Sugaru, and R. H. Schwinger, "Isoform expression of the sarcoplasmic reticulum $\mathrm{Ca} 2+$ release channel (ryanodine channel) in human myocardium," Jour- nal of Molecular Medicine (Berlin, Germany), vol. 78, no. 6, pp. 352-360, 2000.

[155] Y. D. Wang, Y. D. Li, X. Y. Ding et al., “17 $\beta$-Estradiol preserves right ventricular function in rats with pulmonary arterial hypertension: an echocardiographic and histochemical study," The International Journal of Cardiovascular Imaging, vol. 35, no. 3, pp. 441-450, 2019.

[156] M. J. Overbeek, K. T. B. Mouchaers, H. M. Niessen et al., "Characteristics of interstitial fibrosis and inflammatory cell infiltration in right ventricles of systemic sclerosis-associated pulmonary arterial hypertension," International Journal of Rheumatology, vol. 2010, Article ID 604615, 10 pages, 2010.

[157] M. Boehm, N. Arnold, A. Braithwaite et al., "Eplerenone attenuates pathological pulmonary vascular rather than right ventricular remodeling in pulmonary arterial hypertension," BMC Pulmonary Medicine, vol. 18, no. 1, p. 41, 2018.

[158] S. Rain, D. S. G. Bos, M. L. Handoko et al., "Protein changes contributing to right ventricular cardiomyocyte Diastolic Dysfunction in Pulmonary Arterial Hypertension," Journal of the American Heart Association, vol. 3, no. 3, article e000716, 2014.

[159] D. Sacks, B. Baxter, B. C. V. Campbell et al., "Multisociety consensus quality improvement revised consensus statement for endovascular therapy of acute ischemic stroke," International journal of stroke, vol. 13, no. 6, pp. 612-632, 2018.

[160] S. Hsu, K. M. Kokkonen-Simon, J. A. Kirk et al., "Right ventricular myofilament functional differences in humans with systemic sclerosis-associated versus idiopathic pulmonary arterial hypertension," Circulation, vol. 137, no. 22, pp. 2360-2370, 2018.

[161] S. Rain, S. Andersen, A. Najafi et al., "Right ventricular myocardial stiffness in experimental pulmonary arterial hypertension: relative contribution of fibrosis and myofibril stiffness," Circulation. Heart Failure, vol. 9, no. 7, article e002636, 2016.

[162] M. W. Gorr, K. Sriram, A. M. Chinn, A. Muthusamy, and P. A. Insel, "Transcriptomic profiles reveal differences between the right and left ventricle in normoxia and hypoxia," Physiological reports, vol. 8, no. 2, article e14344, 2020.

[163] J. A. Watts, J. Zagorski, M. A. Gellar, B. G. Stevinson, and J. A. Kline, "Cardiac inflammation contributes to right ventricular dysfunction following experimental pulmonary embolism in rats," Journal of Molecular and Cellular Cardiology, vol. 41, no. 2, pp. 296-307, 2006.

[164] L. Tian, F. Potus, D. Wu et al., "Increased Drp1-mediated mitochondrial fission promotes proliferation and collagen production by right ventricular fibroblasts in experimental pulmonary arterial hypertension," Frontiers in Physiology, vol. 9, p. 828, 2018.

[165] H. V. Hwang, N. Sandeep, R. V. Nair et al., “Transcriptomic and functional analyses of mitochondrial dysfunction in pressure overload-induced right ventricular failure," Journal of the American Heart Association, vol. 10, no. 4, article e017835, 2021.

[166] U. K. Ihenacho, K. A. Meacham, M. C. Harwig, M. E. Widlansky, and R. B. Hill, "Mitochondrial fission protein 1: emerging roles in organellar form and function in health and disease," Frontiers in Endocrinology, vol. 12, article 660095, 2021.

[167] J. Nagendran, V. Gurtu, D. Z. Fu et al., "A dynamic and chamber-specific mitochondrial remodeling in right ventricular hypertrophy can be therapeutically targeted," the Journal of thoracic and cardiovascular surgery, vol. 136, no. 1, pp. 168-178.e3, 2008. 